\title{
Quantitative analysis of cooling and lubricating effects of graphene oxide nanofluids in machining titanium alloy Ti6Al4V
}

\author{
Guangxian Li, Shuang Yi, Nan Li, Wencheng Pan, Cuie Wen, Songlin Ding ${ }^{*}$ \\ School of Engineering, RMIT University, Mill Park 3082, Victoria, Australia. \\ School of Computing and Engineering, University of Huddersfield, Huddersfield HD1 3DH, West \\ Yorkshire, UK \\ guangxian.li@ rmit.edu.au, s3516088@student.rmit.edu.au, s3468780@student.rmit.edu.au,w.pan@hud.ac.uk \\ cuie.wen@rmit.edu.au, songlin.ding@rmit.edu.au
}

\begin{abstract}
Ti6Al4V is widely used in industry due to its outstanding mechanical properties. However, the severe abrasion and high temperature at tool/chip and tool/workpiece interfaces cause various types of tool wear in machining Ti6Al4V. To ensure high machining efficiency and high quality of machined surface, cooling fluid is often used to reduce the cutting temperature and friction. In this paper, the cooling and lubricating effects of coolant with graphene oxide nanosheet suspension were investigated experimentally and theoretically. Cutting experiments were conducted to compare the performance of conventional coolant with that of the coolant with graphene oxide nanosheets of different weight percentages $(0.1 \%$ and $0.5 \%)$. Cutting force and temperature on the rake face were measured in each cutting pass. A theoretical model based on computational fluid dynamics (CFD) was developed to investigate the temperature distribution and cooling efficiency quantitatively. Friction force and coefficient of friction at tool/chip interface and tool/workpiece interface were calculated to analyse the lubrication effects of different types of coolant. The results showed that the performance of cooling and lubrication of the coolant became better with the addition of graphene oxide nanosheets. Results from the analysis of flank wear and crater wear and the morphological characteristics proved that there was a significant further reduction in cutting temperature and friction force when coolant with graphene oxide nanosheets was used.
\end{abstract}


Keywords: Coolant, graphene oxide nanosheets, cooling, lubrication, cutting temperature, friction force, tool wear 


\section{Introduction}

Ti6Al4V is the most widely-used titanium alloy in industry due to its outstanding properties including low density, high strength and exceptional corrosion resistance (Oosthuizen et al., 2010). However, in machining Ti6Al4V, the harsh cutting conditions at the tool/chip and tool/workpiece interfaces result in various types of severe tool wear, which significantly reduce tool life and eventually cause the failure of the cutting tool. Furthermore, due to the low thermal conductivity $\left(6.7 \mathrm{Wm}^{-1} \mathrm{~K}^{-1}\right)$ and high strain rate, a huge amount of heat is generated in cutting Ti6Al4V (Amin et al., 2007); the high cutting temperature at tool/chip interface and tool/workpiece interface leads to thermal-induced damages on the cutting tool and machined surfaces. To increase the machining efficiency and ensure the quality of machined surface, coolant or metalworking fluid with excellent cooling and lubricating properties has to be used to reduce the cutting temperature as well as the friction at tool/chip and tool/workpiece interfaces.

Researches on developing new approaches to improve cooling and lubrication effects have been conducted for many years in both academia and industry. Oil was the most widely-used cutting fluid in metal cutting processes decades ago (El Baradie, 1996a). Owing to their better performance in highspeed cutting, water-based cutting fluids replaced cutting oil later on (El Baradie, 1996b). Nowadays, various cooling methods including cryogenic cooling, minimum quantity lubrication (MQL) and coolant with nanoparticle suspension have been developed to achieve better cooling and lubrication effects (Debnath et al., 2014).

Cryogenic cooling uses liquid gas (generally liquid nitrogen $\mathrm{LN}_{2}$ ) to create an extremely-lowtemperature environment $\left(-150{ }^{\circ} \mathrm{C}\right.$ to $\left.-180{ }^{\circ} \mathrm{C}\right)$ to reduce the temperature in metal cutting processes (Yildiz and Nalbant, 2008). Dhananchezian et al. (Dhananchezian and Kumar, 2011) found, by comparing with that of using conventional coolant, the surface roughness was reduced by $35 \%$ and the tool life became 39\% longer with the application of cryogenic cooling in turning Ti6A14V. With the application of cryogenic cooling, Ahmed et al. (Ahmed and Kumar, 2016) found that surface roughness, cutting force and cutting temperature were reduced by 52\%, $10 \%$ and $61 \%$ respectively in drilling 
Ti6Al4V. However, the complicated cooling devices and the strict safety requirement on storing a huge amount of liquid $\mathrm{LN}_{2}$ are the obstacles hindering the wide application of cryogenic machining in industry (Jayal et al., 2010). To meet the requirement of cleaner production, MQL was developed to avert the environment problem caused by the massive use of oil-based metalwork fluids. Compared with conventional coolant, the amount of cooling liquid used in MQL was significantly reduced but the ability of lubrication was increased. This made MQL a promising and eco-friendly cooling method in metal-cutting works (Sharma et al., 2016). However, it was also found by some researchers that the performance of MQL in cutting hard-to-machine materials was not as good as expected. For example, Su et al. reported that the cooling efficiency of MQL was limited in machining superalloys due to its low cooling capacity (Su et al., 2007); whereas in the turning experiment conducted by Leppert et al., it was found that the reduction of cutting force when using MQL was not obvious, compared with that of using conventional cutting fluids (Leppert and Peng, 2012).

Since the pioneering work made by Choi et al in 1995 (Choi, 2009), extensive research has been conducted on applying nanofluids as a new heat transfer fluid (Taylor et al., 2013). Commercial products of nanofluids for machining including turning, milling and drilling have already been available in the global market. These products have been applied by various companies in manufacturing industry and resulted in significant reductions of manufacturing costs (Derek, K., 2014). Nanofluids are applied in metal cutting works because of their better capability on enhancing the performance of heat transfer (Sidik et al., 2017). The thermal properties of the nanofluids are influenced by the types of nanoparticles and the volume or mass fraction (Phuoc et al., 2011). Among different metallic oxides, $\mathrm{Al}_{2} \mathrm{O}_{3}$ nanoparticles were the widely-used compound in making nanofluids (Chandrasekar et al., 2012). It was found that $\mathrm{Al}_{2} \mathrm{O}_{3}$ of $13 \mathrm{~nm}$ with the volume fraction of $13 \%$ increased the thermal conductivity of water by $30 \%$ (Sharma et al., 2015). By adding nanoparticles of $\mathrm{CuO}, \mathrm{Al}_{2} \mathrm{O}_{3}$ and $\mathrm{ZnO}_{2}$ with the weight fraction $40 \%$ (Vajjha and Das, 2009), Vajjha and Das found that the thermal conductivities of the nanofluids were increased by $60 \%, 69 \%$ and $48.5 \%$ respectively. In addition to metallic oxides, nanoparticles of other compounds have been attempted as well to make nanofluids with better physical and mechanical properties. For example, Li et al. (Li et al., 2014) added $\mathrm{MoSe}_{2}$ powders 
into oil-based coolant liquid to make mixed nanofluids in friction tests and found that the new nanofluids showed better friction-and-wear properties because of the formation of a tribofilm at the sliding interface. Gajrani et al. (Gajrani et al., 2019) investigated the nanofluids consisting of commercial mineral oil and $0.3 \%$ nanoparticles $\left(\mathrm{MoS}_{2}\right.$ and $\left.\mathrm{CaF}_{2}\right)$, and an average increase of $15 \%$ in the overall thermo-conductivity of the cutting fluid was achieved. Sridharan and Malkin (Sridharan and Malkin, 2009) compared the performance of nanofluids which consisted of oil and two kinds of nanoparticles, carbon nanotubes (CNT) and $\mathrm{MoS}_{2}$ respectively, and found CNT nanofluids had better performance on lubrication compared with that of $\mathrm{MoS}_{2}$ nanofluids. CNT nanofluids were often applied combinedly with MQL to improve the cooling and lubrication effects. In the experiment conducted by Prabhu and Vinayagam (Prabhu and Vinayagam, 2011), better surface finishing was obtained with the hybrid strategy (CNT nanofluids+MQL) in comparison with that of single MQL.

The nanosheets of graphite have a unique lattice structure. This structure increases the contact area between the nanosheets and the friction pair, and provides better lubrication effect in metal-cutting processes (Lv et al., 2018). Huang et al. (Huang et al., 2006) pointed out that adding graphite into oil and using it as cutting fluids could reduce cutting force and tool wear. The reduction in cutting temperature was $58 \%$ in the study conducted by Samuel et al. (Samuel et al., 2011), and the improvement of lubrication and the reduction of cutting force were $59 \%$ and $26 \%$ respectively. Similar to graphite nanosheets, graphene oxide is a kind of nano-material consisting of two-dimensional sheets. This material is hydrophilic and can be dispersed in water to form stable colloidal suspensions (Stankovich et al., 2007). Also, the graphene oxide nanosheets has a relative high thermal conductivity ranging from 600 to $5000 \mathrm{~W} \cdot \mathrm{m}^{-1} \cdot \mathrm{K}^{-1}$ (Zhu et al., 2010). Both reasons made graphene oxide a type of promising material as added suspension in cutting fluid in metal-cutting processes. In the experimental research of Smith et al. (Smith et al., 2015), the temperature could be reduced by $50 \%$ by using the coolant with graphene oxide nanosheet suspension. Singh et al. (Singh et al., 2018) investigated the influences of water-based graphene nanofluids with different mass concentration on the cutting temperature and surface roughness $(\mathrm{Ra})$ in milling processes, and it was found that the Ra and temperature were significantly reduced with the increase in the mass concentration of graphene. In 
the cutting experiment conducted by Li et al. ( $\mathrm{Li}$ et al., 2019), the nanofluid consisting of graphene and vegetable oil was applied in combination with MQL. They used Taguchi Method to investigate the influence of the hybrid coolant on surface roughness, hardness, cutting temperature and cutting force, and found that the improvement rates were $24.82 \%, 8.36 \% 13.59 \%$ and $18.13 \%$ respectively.

However, although the addition of nanoparticles in cutting fluids can improve the overall thermal properties of the coolant, the application of fluid with metallic nanoparticles could cause scratches on the machined surface due to the agglomeration of the hard nanoparticles. Zhang et al. applied $\mathrm{MoSe}_{2}$ nanoparticles in MQL when grinding Ni-based alloys (Zhang et al., 2016), and found that the roughness of machined surface increased when the cutting fluid with larger concentration of nanoparticles was applied. They concluded that the agglomeration of the hard nanoparticles could deteriorate the quality of machined surface. Similarly, in the experiment conducted by Nam et al. (Nam et al., 2011), the nanofluid consisting of $30 \mathrm{~nm}$ nanodiamond particles and oil were used in drilling Al6061. Scratches were found on the hole surface although the torque and thrust force were reduced when using diamond nanofluids.

Nanofluids can reduce both cutting temperature and cutting force; the types, sizes and concentration of the nanoparticles influence the performance of nanofluids in the cutting process. However, current research is limited to experimental investigations, most of the results on the performance of nanofluids are obtained via experimental results, there is a lack of in-depth theoretical analysis of the cooling and lubrication mechanisms of nanofluids. In this paper, the performance and mechanism of cooling and lubrication of coolants with graphene oxide nanosheet suspension were investigated quantitatively. A new hybrid FEM-analytical model was developed to describe the heat convection among the cutting tool, workpiece and nanofluids. The lubricant mechanism at two different tribo-systems, tool/chip interface and tool/workpiece interface, were analysed and discussed. Additional turning experiments using conventional cutting fluids and graphene oxide suspended fluid were conducted. Titanium alloy Ti6A14V was machined with PCBN inserts with both conventional coolant and cutting fluids with graphene oxide nanosheet suspension. The results of this research will provide useful information to the industry and pave the way for further research in this area. 


\section{Experiment}

\subsection{Experimental setup}

The experiment was conducted to investigate the cooling and lubrication effects of coolant with graphene nanosheet suspension in cutting processes. Three types of coolant were used in the experiment: conventional coolant (Con_Cool), coolant mixed with $0.1 \%$ weight percentage (w.t.) nanosheets $\left(\mathrm{GraO} \_0.1 \%\right)$ and coolant mixed with $0.5 \%$ weight percentage nanosheets $\left(\mathrm{GraO} \_0.5 \%\right)$. The base liquid for the nanofluids was industrial metalwork coolant (ROCOL Ultracut Clear) and the addition was graphene oxide nanosheets made by Sigma Aldrich. The properties of the metalwork coolant and added nanosheets were listed in Table 1 and Table 2 respectively. Fig. 1(a) shows the morphology of graphene oxide nanosheets under transmission electron microscopy (TEM). To prepare the new coolant mixed with graphene oxide nanosheets, the powder of nanosheets was weighed and added into $1 \mathrm{~kg}$ conventional coolant. Firstly, the graphene oxide nanosheets of different weights were mixed with $100 \mathrm{~mL}$ conventional coolant, and the $100 \mathrm{~mL}$ nanofluid was processed via ultrasonic vibration at the frequency of $25 \mathrm{kHz}$ in order to break large blocks of nanosheets in the liquid. The 100 $\mathrm{mL}$ nanofluid was poured into the $1 \mathrm{~kg}$ Con_Cool afterwards and the mixed liquid was pumped for 30 min to make the nanosheets dispersed thoroughly in the liquid. The whole mixing process was repeated before every cutting test to ensure the uniform distribution of the nanosheets in the coolant. The samples of the three kinds of coolant used in the cutting experiment are shown in Fig. 1(b).

Table 1 Property and composition of ROCOL Ultracut Clear

\begin{tabular}{lllll}
\hline Density $(\mathrm{g} / \mathrm{cm} 3)$ & Mineral oil & Natural oil & Water & Others \\
\hline 0.95 & $20 \%$ & $20 \%$ & $60 \%$ & $<1 \%$ \\
\hline
\end{tabular}

Table 2 Properties of Sigma Aldrich graphene oxide nanosheets

\begin{tabular}{lllll}
\hline Purity & Thickness $(\mathrm{nm})$ & Diameter $(\mathrm{nm})$ & Layers & Specific surface area \\
\hline $99 \%$ & $1-1.77$ & $0.5-5$ & $1-5$ & $300-450$ \\
\hline
\end{tabular}



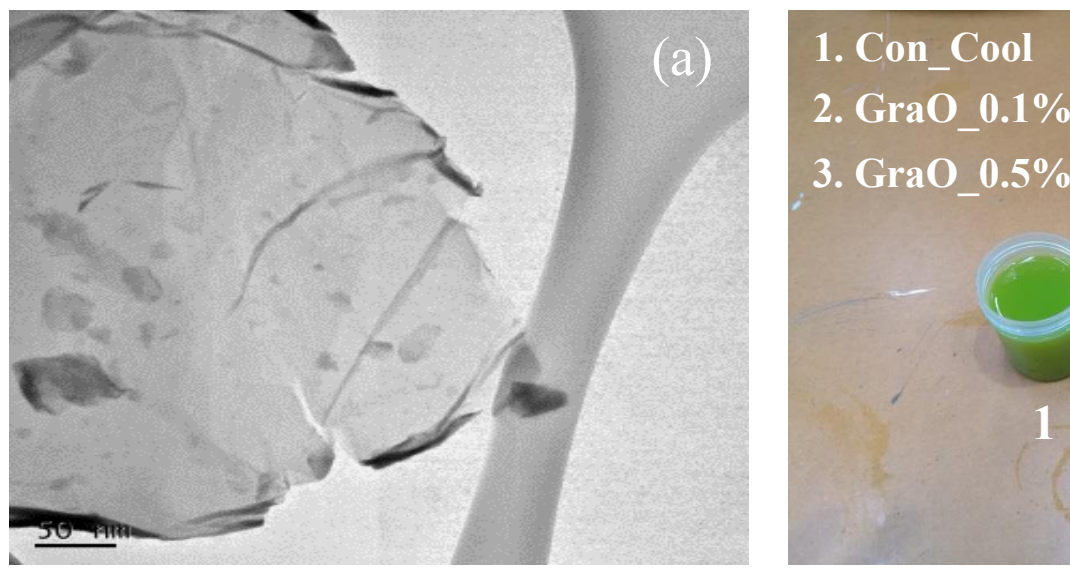

Fig. 1 (a) Morphology of graphene oxide nanosheet under transmission electron microscopy (b) three kinds of coolant

Ti6Al4V rods of the diameter of $20 \mathrm{~mm}$ were used as the workpiece, and CBN tools (SECO) with the $6^{\circ}$ rake angle and $10^{\circ}$ clearance angle were used in the experiments. Fig. 2(a) presents the experimental setup for the cutting test. The experiment was to turn the titanium alloy on a CNC vertical machining centre (HAAS VF1R160). To test the performance of the coolants at different cutting speeds and under different pressures, cutting speeds of $80 \mathrm{~m} / \mathrm{min}, 160 \mathrm{~m} / \mathrm{min}$ and $240 \mathrm{~m} / \mathrm{min}$ were selected as the low, normal and high cutting speeds; whereas pressures of 1 bar and 10 bar were adopted as the low and high coolant pressures to test the performance of the nanofluids under two extreme pressures. The cutting depth and feed rate were $0.1 \mathrm{~mm}$ and $0.05 \mathrm{~mm} / \mathrm{rev}$ and they were fixed throughout the experiments.

In each cutting pass, the signals of main cutting force ( $\mathrm{Y}$ direction/tangential direction), feed force ( $\mathrm{Z}$ direction/axial direction) and back force (X direction/radial direction) were obtained by the force measurement system including a 3-axis dynamometer (Kistler 9257B), an amplifier (Kistler 5070A), a DAQ card (National Instrument 6036E) and the software program SignalExpress. Also, a K-type thermocouple (OMEGA 5TC-TT-K-40-36) was used to measure the average temperature in each cutting pass. A slot was machined near the tool tip via wire electrical discharge machining to fix the temperature sensor on the rake face. The thermocouple was then calibrated by using a thermocouple calibrator (MS7220) to ensure the accuracy and reliability of the measurements. The forces and 
temperatures when they became steady during the cutting process (Fig. 2(b) and 2(c)) were recorded as cutting force and cutting temperature for analysis in section 2.2.

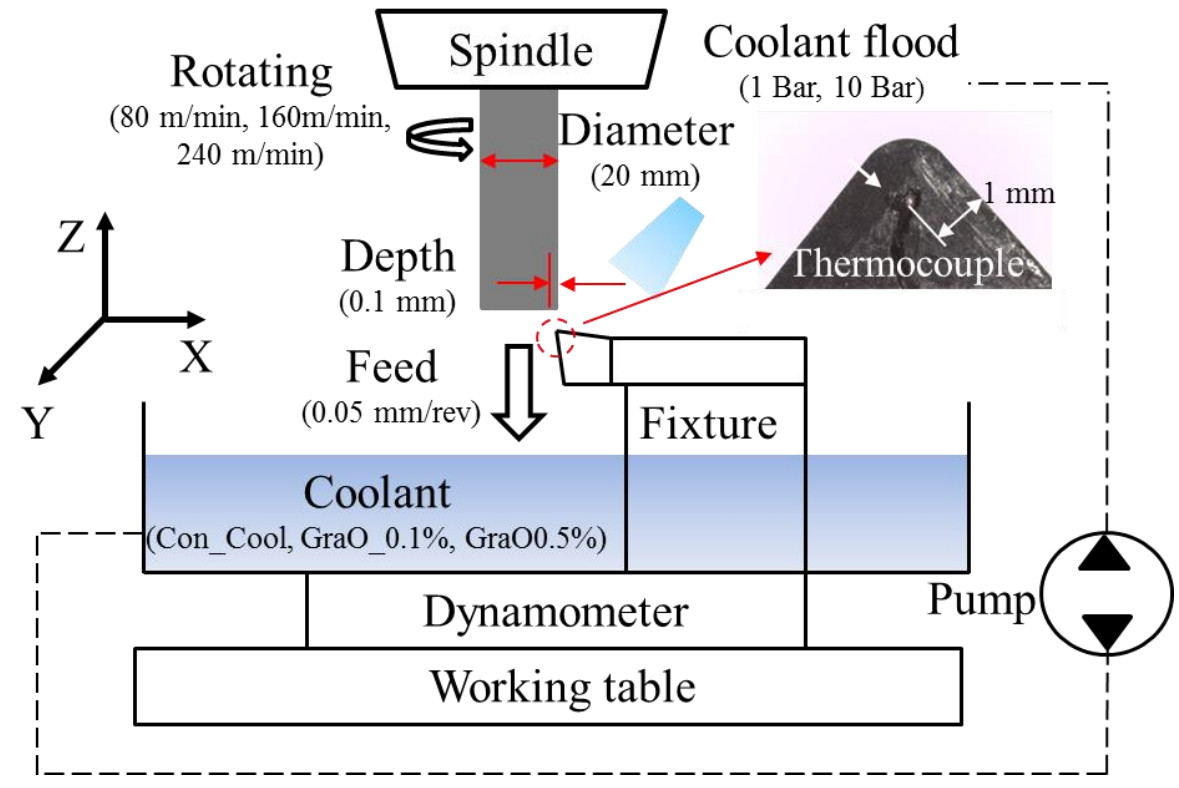

(a)

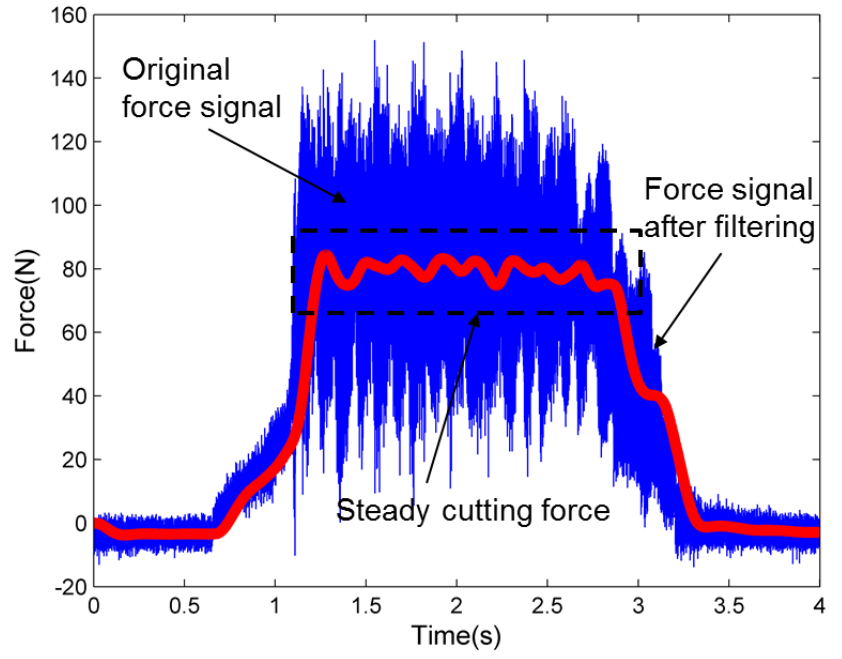

(b)

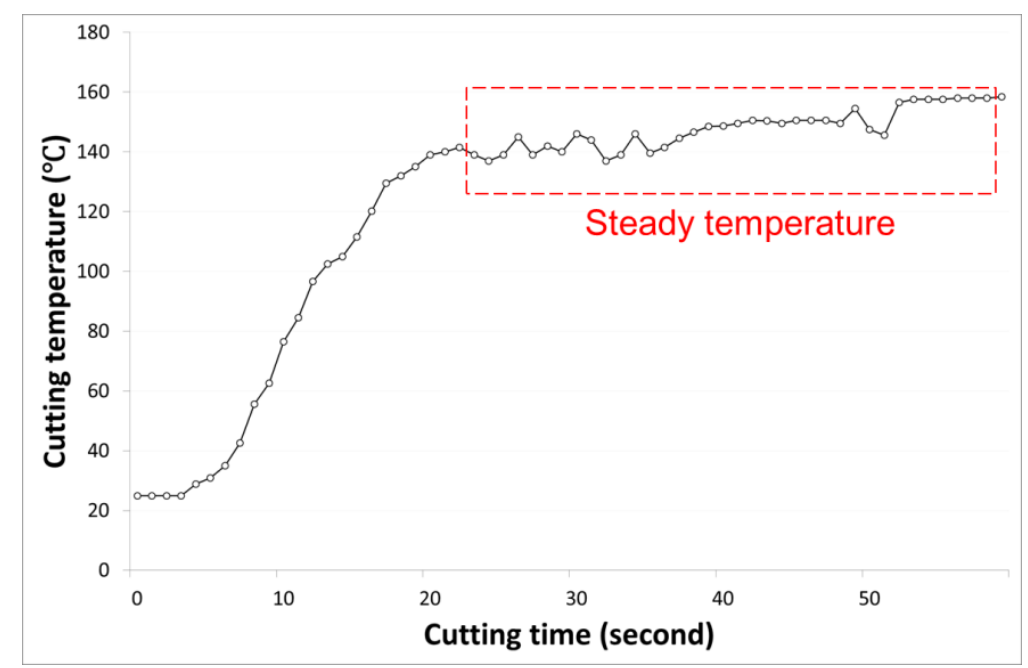

(c)

Fig. 2 (a) Experimental setup of the cutting test (b) measured cutting force (c) measured temperature

\subsection{Experimental results}

Fig. 3 presents the average cutting temperature measured at the position $1 \mathrm{~mm}$ away from the cutting edge. It was found that the temperature decreased with the application of $\mathrm{GraO}_{-} 0.1 \%$ and $\mathrm{GraO} \_0.5$, which proved the better cooling effect of graphene oxide nanofluids. Specifically, under 1 bar pressure, 
the temperature reductions at different cutting speeds were averagely $15{ }^{\circ} \mathrm{C}$ and $35{ }^{\circ} \mathrm{C}$ when $\mathrm{GraO} \_0.1$ and $\mathrm{GraO} \_0.5$ were used. The larger reduction of temperature when using $\mathrm{GraO} \_0.5$ indicates that the better heat transferring capability of the nanofluid with high-concentration nanoparticles, which was in accordance with the result of Singh (Singh et al., 2018). Under the pressure of 10 bar, the cutting temperatures were lower with the application of low coolant pressure because more amount of heat was transferred away by the coolant with larger flow velocity. The pressure did not cause significant influence on the temperature reduction of $\mathrm{GraO}_{-} 0.1 \%$. In contrast, the average temperature reduction under high pressure was $25{ }^{\circ} \mathrm{C}$ when using GraO_0.5\%, which was smaller than that of under the pressure of 1 bar. Furthermore, the influence of the concentration of graphene oxide nanosheets on temperature was less obvious under 10 bar pressure, compared with the temperature reduction under 1 bar pressure. The reduction of temperature was within $10{ }^{\circ} \mathrm{C}$ when increasing the concentration of graphene oxide nanosheets at the cutting speeds of $80 \mathrm{~m} / \mathrm{min}$ and $160 \mathrm{~m} / \mathrm{min}$. This phenomenon is consistent with the findings made by Smith et al. (Smith et al., 2015) because the cooling ability of the nanofluids reached the threshold value when $0.5 \%$ graphene oxide nanosheets was added.

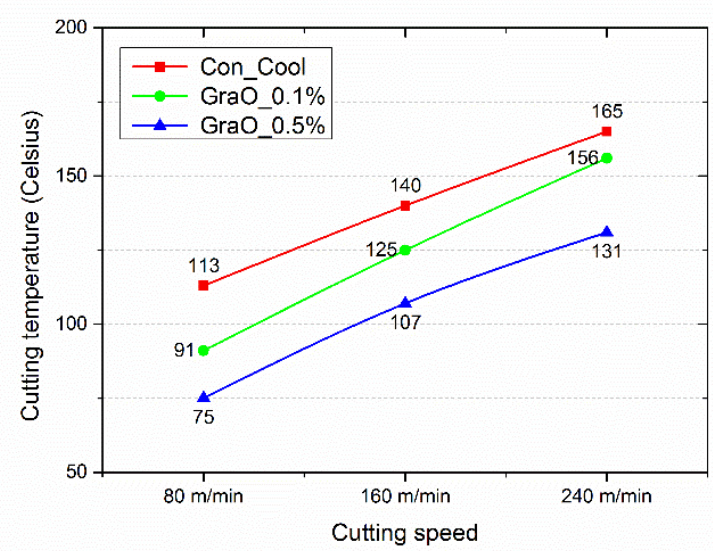

(a)

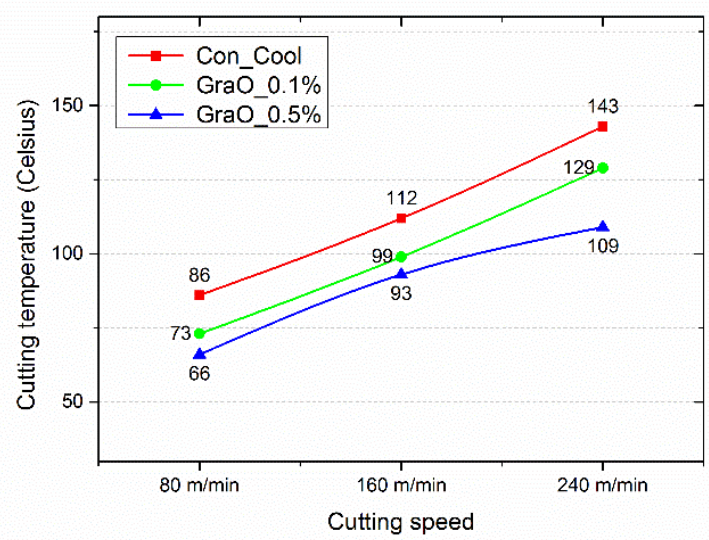

(b)

Fig. 3 Measured cutting temperature under different cutting conditions (a) temperatures under1 bar coolant pressure (b) temperatures under 10 bar coolant pressure

Fig. 4 shows the measured values of main cutting force and feed force in each cutting pass. From Fig. 4(a) and Fig. 4(b), it is found that the main cutting force decreased with the increase of the concentration 
of graphene oxide nanosheets in the cooling fluid, which agrees with the findings about nanofluids in cutting processes made by Zhang et al. (Zhang et al., 2016)). The force reduction was around $30 \mathrm{~N}$ and $40 \mathrm{~N}$ when the concentration of the coolant was $0.1 \%$ w.t. and $0.5 \%$ w.t ( 1 bar pressure). The maximum reduction was found when the cutting speed was $80 \mathrm{~m} / \mathrm{min}$, specifically, the main cutting force was reduced by $56 \mathrm{~N}$ and $87 \mathrm{~N}$ respectively when coolants of $\mathrm{GraO} \_0.1 \%$ and $\mathrm{GraO} \_0.5 \%$ were adopted. The main cutting force was smaller under the higher coolant pressure compared with that under the normal pressure. The average force reduction when using $\mathrm{GraO} \_0.1 \%$ and $\mathrm{GraO} \_0.5 \%$ were $20 \mathrm{~N}$ to $40 \mathrm{~N}$. The reduction of main cutting force could be ascribed to the lubrication effect of nanofluids at the tool/workpiece interface. Based on the lubrication mechanism of Gajrani et al. (Gajrani et al., 2019), the nanofluids could reach the friction interface due to the vibration of the tool and workpiece system. A tribo-film consisting of liquid and nanoparticles reduced the abrasion between the cutting tool and workpiece, which caused the reduction of main cutting force. In comparison, the influences of the type and the pressure of coolant on feed force were insignificant. The change of feed force did not present an obvious trend with the increase of the concentration of graphene oxide nanosheets. The forces under different cooling conditions fluctuated around $63 \mathrm{~N}$ when cutting speeds were $80 \mathrm{~m} / \mathrm{min}$ and $160 \mathrm{~m} / \mathrm{min}$. Minor increments on feed forces could be found at the cutting speed of $240 \mathrm{~m} / \mathrm{min}$.
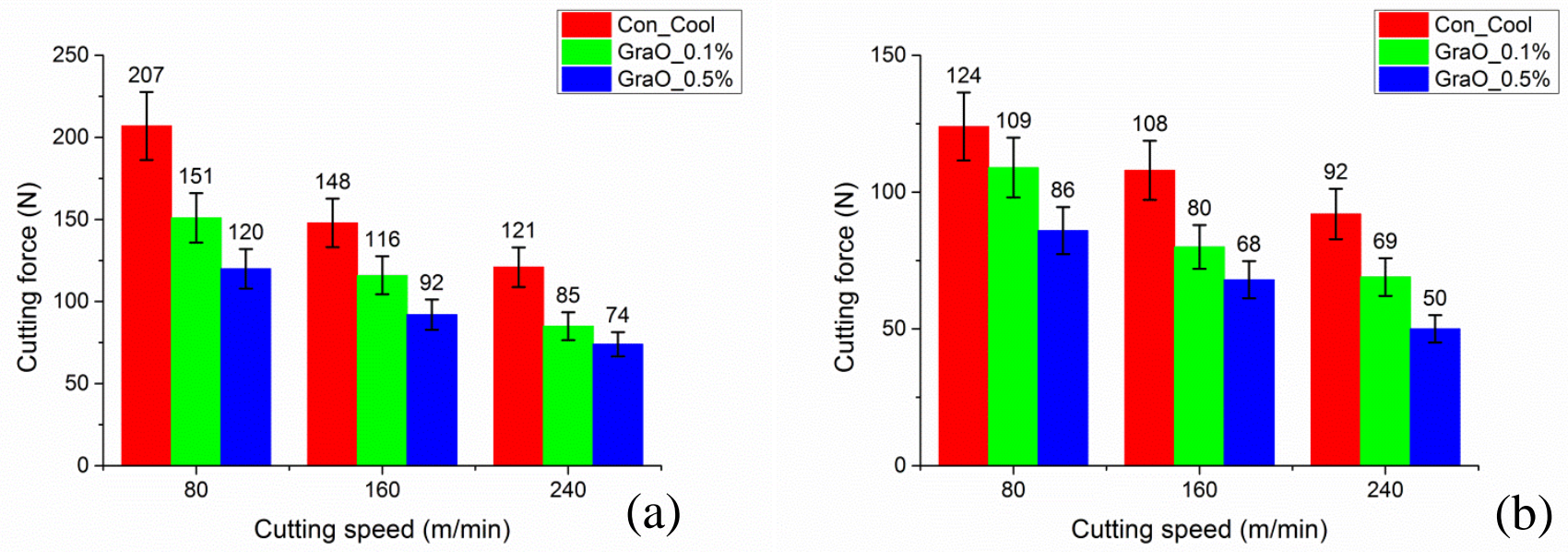

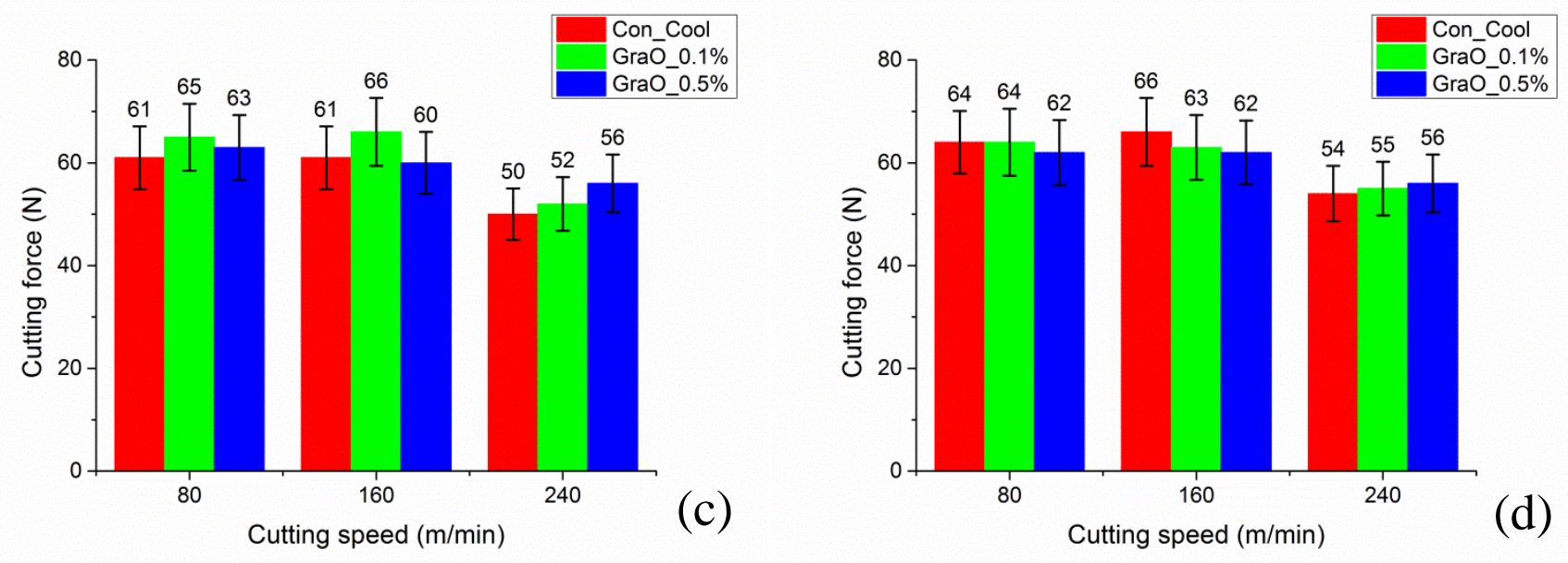

Fig. 4 Cutting forces under different cutting conditions (a) main cutting forces under 1-bar coolant pressure (b) main cutting forces under 10-bar coolant pressure (c) feed forces under 1-bar coolant pressure (d) feed forces under10-bar coolant pressure

\section{Analysis of cooling effects}

\subsection{Modelling of the cooling process}

To further investigate the cooling effects of three kinds of coolant theoretically, a hybrid CFD-analytical model was developed to describe the heat transfer during the cutting processes. It is known that the status of liquid flow including temperature $T$ and pressure $p$ is governed by the continuity equation, the momentum equation and energy equation (Tu et al., 2018). In this study, the cooling process in cutting was solved as a two-dimensional problem; therefore, the governing equations of the dynamic coolant are simplified as follows:

Continuous equation: $\frac{\partial \boldsymbol{u}}{\partial x}+\frac{\partial \boldsymbol{v}}{\partial y}=0$

Momentum equation: $\left\{\begin{array}{l}\rho\left(\boldsymbol{u} \frac{\partial \boldsymbol{u}}{\partial x}+\boldsymbol{v} \frac{\partial \boldsymbol{u}}{\partial y}\right)=-\frac{\partial p}{\partial x}+\mu\left(\frac{\partial^{2} \boldsymbol{u}}{\partial x^{2}}+\frac{\partial^{2} \boldsymbol{u}}{\partial y^{2}}\right) \\ \rho\left(\boldsymbol{u} \frac{\partial \boldsymbol{v}}{\partial x}+\boldsymbol{v} \frac{\partial \boldsymbol{v}}{\partial y}\right)=-\frac{\partial p}{\partial y}+\mu\left(\frac{\partial^{2} \boldsymbol{v}}{\partial x^{2}}+\frac{\partial^{2} \boldsymbol{v}}{\partial y^{2}}\right)\end{array}\right.$

Energy equation: $\rho c\left(\boldsymbol{u} \frac{\partial T}{\partial x}+\boldsymbol{v} \frac{\partial T}{\partial y}\right)=K\left(\frac{\partial^{2} T}{\partial x^{2}}+\frac{\partial^{2} T}{\partial y^{2}}\right)+\mu\left\{2\left[\left(\frac{\partial \boldsymbol{u}}{\partial x}\right)^{2}+\left(\frac{\partial \boldsymbol{v}}{\partial y}\right)^{2}\right]+\left(\frac{\partial \boldsymbol{u}}{\partial x}+\frac{\partial \boldsymbol{v}}{\partial y}\right)^{2}\right\}$ 
where $\boldsymbol{u}$ and $\boldsymbol{v}$ are the two orthogonal directions in Cartesian coordinate system.

The simulation of the cooling process was conducted in ANSYS Fluent, the sketch of workpiece, chip flow, cutting tool and coolant fluid were modelled in SOLIDWORKS 2017, and then imported and meshed in ANASYS Meshing. When developing the CFD model, the status of coolant fluid follows the following assumption:

1. the liquid of coolant is incompressible and viscous;

2. the change in density, viscosity, and thermal conductivity of the coolant liquids are negligible;

3. the heat exchanges at the interfaces are stable.

In a metal cutting process, heat is generated by the shear deformation of workpiece material in primary deformation zone and by the tool/chip friction in the secondary deformation zone, and a proportion of the heat is transferred to the cutting tool via the tool/chip interface. The modelling of heat source was based on the theory proposed by Komanduri and Hou (Komanduri and Hou, 2001). Specifically, the temperature rise on the tool side was caused by the heat transfer from stationary rectangular heat source to the tool rake face via the tool/chip contact region, and the boundary on the tool side (OD) is adiabatic (Fig. 5(b)). As a result, a line heat source with the length of tool/chip contact should be modelled at the tool/chip interface. To ensure the availability of the calculation in ANASYS, the heat source was modelled as a narrow groove $(1 \mu \mathrm{m})$ and the gap between the heat source and the tool rake face was controlled to be close enough (Fig. 5(c)). The heat was transferred by convection processes at the interfaces of coolant fluid and tool faces, and the boundary conditions on the faces of the tools (DA, $\mathrm{AB}, \mathrm{BC}$ and $\mathrm{CO}$ ) can be presented by equations (5) to (7).

$$
\begin{aligned}
& O D: Q_{\text {tool-chip }}=\left.K_{\text {tool }} \frac{\partial^{2} T}{\partial v}\right|_{u=0,0 \leq v \leq v_{D}} \\
& D A: Q_{\text {coolant_1 }}=\left.H_{\text {coolant }_{1}} \frac{\partial^{2} T}{\partial v}\right|_{u=0, v_{D} \leq v \leq v_{A}} \\
& A B: Q_{\text {coolant_2 }}=\left.H_{\text {coolant }_{2}} \frac{\partial T}{\partial u \partial v}\right|_{0 \leq u \leq u_{B}, v=v_{A}} \\
& B C: Q_{\text {coolant_3 }}=\left.H_{\text {coolant }_{3}} \frac{\partial T}{\partial u \partial v}\right|_{u=u_{B}, 0 \leq v \leq v_{B}}
\end{aligned}
$$




$$
\text { CO: } Q_{\text {coolant } \_4}=\left.H_{\text {coolant }_{4}} \frac{\partial^{2} T}{\partial u}\right|_{v=0,0 \leq u \leq u_{C}}
$$
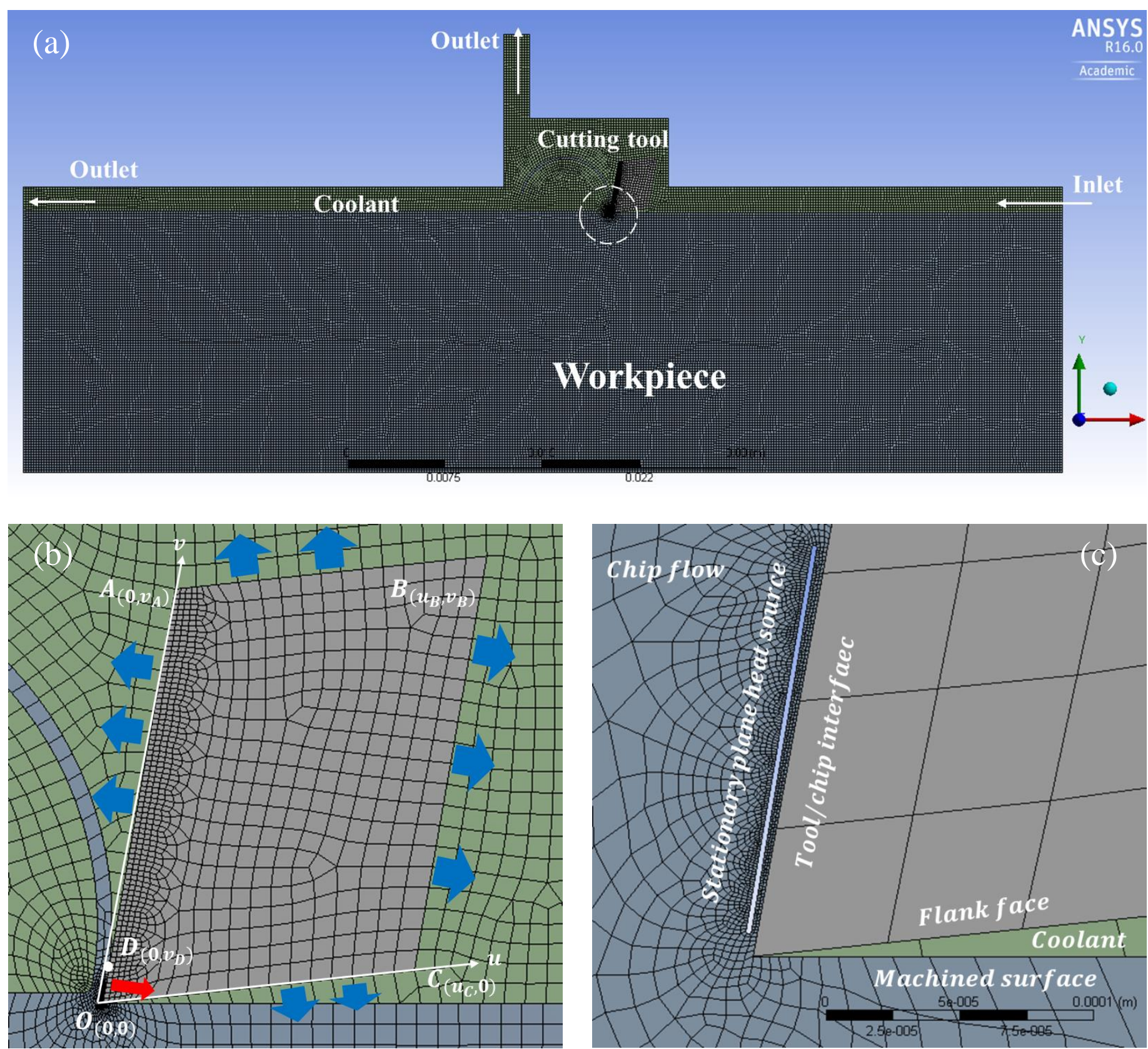

Fig. 5 (a) the CFD model of the cooling process in ANASYS R16.0 (b) boundary conditions at the faces of the cutting tool (c) stationary plane heat source on the side of the chip

Density, thermal conductivity and specific heat of the coolant changed with the concentration of graphene oxide nanosheets, which can be calculated with the following equations (Behroyan et al., 2016; Hadadian et al., 2014; Zhou and Ni, 2008), and the results are listed in Table 3. 


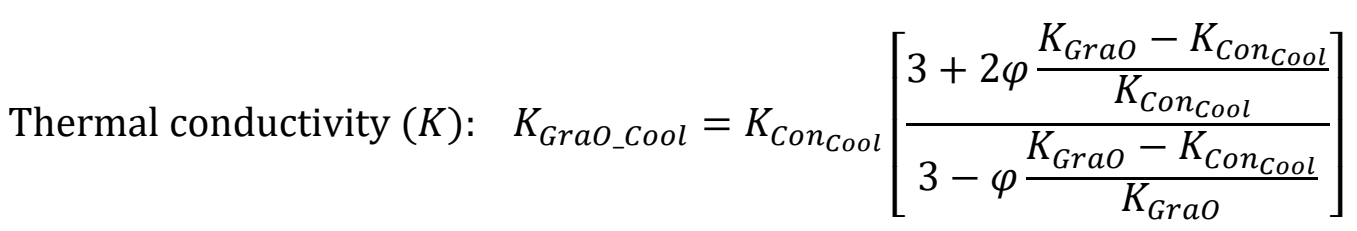

Density $(\rho): \quad \rho_{\text {GraO_Cool }}=(1-\varphi) \rho_{\text {Con_Cool }}+\varphi \rho_{\text {GraO }}$

Specific heat $(C): C_{G r a O_{-} C o o l}=\frac{\varphi\left(\rho_{\text {GraO }} \cdot C_{\text {GraO }}\right)+(1-\varphi)\left(C_{\text {Con_Cool }} \cdot \rho_{\text {Con_Cool }}\right)}{\rho_{\text {GraO_Cool }}}$

where $\varphi$ is the weight percentage of the graphene oxide nanopowder.

Table 3 Physical and thermal properties of different kinds of coolant

\begin{tabular}{lccc}
\hline Coolant & Density & $\begin{array}{c}\text { Thermal conductivity } \\
\left(W \cdot m^{-1} K^{-1}\right)\end{array}$ & $\begin{array}{c}\text { Specific heat } \\
\left(\mathrm{J} \cdot g^{-1{ }^{\circ}} \mathrm{C}^{-1}\right)\end{array}$ \\
\hline Con_Cool & 0.94 & 0.249 & 3.24 \\
GraO_0.1\% & 0.94 & 0.253 & 3.24 \\
GraO_0.5\% & 0.94 & 0.267 & 3.24 \\
\hline
\end{tabular}

Heat flux to the cutting tool via the tool/chip interface was calculated by the established analytical model. The heat flux $q$ in the 2-D heat transfer problem is calculated with the following equation:

$$
q=\frac{Q}{L_{\text {tool-chip }}}
$$

where $L_{\text {tool-chip }}$ is the tool/chip contact length.

As introduced in the aforementioned section, the rise of tool temperature was caused by the heat transferred from the stationary heat source via the tool/chip interface. Fig. 6(a) shows the heat transfer to the cutting to via the tool/chip interface. The total amount of heat transferred to the cutting tool $(Q)$ was influenced by both the heat generated in primary deformation zone $Q_{\text {primary }}$ and in secondary deformation zone $Q_{\text {secondary }}$ (Yan et al., 2014). $Q_{\text {primary }}$ and $Q_{\text {secondary }}$ can be calculated as follows:

$$
\begin{gathered}
Q_{\text {primary }}=F_{S} V_{s}=\left(F_{z} \cos \theta-F_{x} \sin \theta\right) \frac{\mathrm{V} \cos \alpha \cos \theta}{\sin \theta \sin \alpha+\cos \alpha \cos \theta} \\
Q_{\text {secondary }}=F_{f} V_{c}=\left(F_{x} \cos \alpha-F_{z} \sin \alpha\right) \frac{\mathrm{V} \sin \theta}{\sin \theta \sin \alpha+\cos \theta \cos \alpha}
\end{gathered}
$$


where, $F_{S}, F_{f}, V_{S}, V_{c}$ stand for shear force in primary shear zone, friction force at tool/chip interface, the shear velocity and the velocity of chip flow on rake face respectively (Fig. 6(b)). $R_{\text {chip }}$ is the partition of the heat to chip flow, and the value was set as 0.82 based on the empirical results of relevant experiments (Egana et al., 2012). $Q_{\text {primary }}$ and $Q_{\text {secondary }}$ were calculated by adopting the measured cutting forces, geometric parameters and the cutting speeds, and the results are listed in Table 4

Table $4 Q_{\text {primary }}$ and $Q_{\text {secondary }}(\mathrm{W})$ under different cooling conditions

\begin{tabular}{l|ccc|ccc}
\hline \multicolumn{7}{l}{$Q_{\text {primary }}$} \\
\hline Coolant pressure & \multicolumn{5}{c|}{1 bar } & \multicolumn{3}{c}{10 bar } \\
\hline Cutting speed & $80 \mathrm{~m} / \mathrm{min}$ & $160 \mathrm{~m} / \mathrm{min}$ & $240 \mathrm{~m} / \mathrm{min}$ & $80 \mathrm{~m} / \mathrm{min}$ & $160 \mathrm{~m} / \mathrm{min}$ & $240 \mathrm{~m} / \mathrm{min}$ \\
\hline Con_Cool & 233.53 & 330.17 & 388.41 & 134.31 & 231.36 & 268.62 \\
Gra_0.1\% & 163.35 & 248.23 & 290.4 & 114.95 & 163.88 & 203.28 \\
GraO_0.5\% & 133.1 & 180.75 & 228.69 & 98.01 & 139.78 & 145.2 \\
\hline$Q_{\text {secondary }}$ & \multicolumn{7}{c}{10 bar } \\
\hline Coolant pressure & $1 \mathrm{bar}$ & & \\
\hline Cutting speed & $80 \mathrm{~m} / \mathrm{min}$ & $160 \mathrm{~m} / \mathrm{min}$ & $240 \mathrm{~m} / \mathrm{min}$ & $80 \mathrm{~m} / \mathrm{min}$ & $160 \mathrm{~m} / \mathrm{min}$ & $240 \mathrm{~m} / \mathrm{min}$ \\
\hline Con_Cool & 51.87 & 130.34 & 200 & 67.83 & 140.98 & 212 \\
GraO_0.1\% & 61.18 & 143.64 & 200 & 73.15 & 146.3 & 220 \\
GraO_0.5\% & 49.21 & 114.38 & 192 & 58.52 & 127.68 & 204 \\
\hline
\end{tabular}

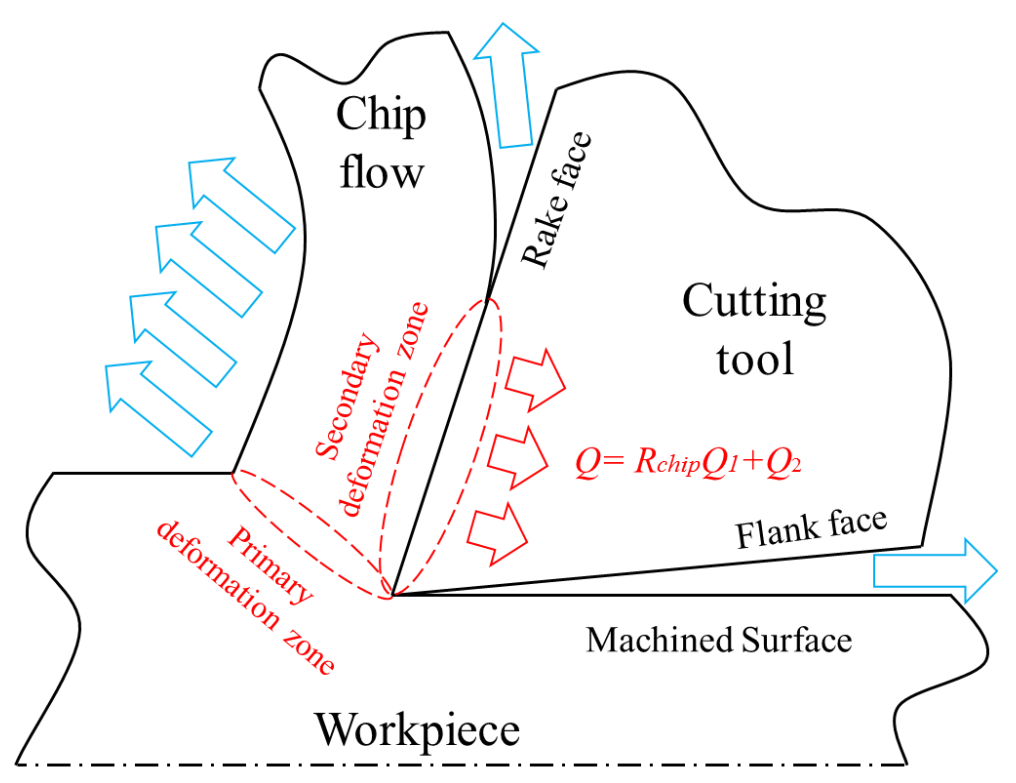

(a)

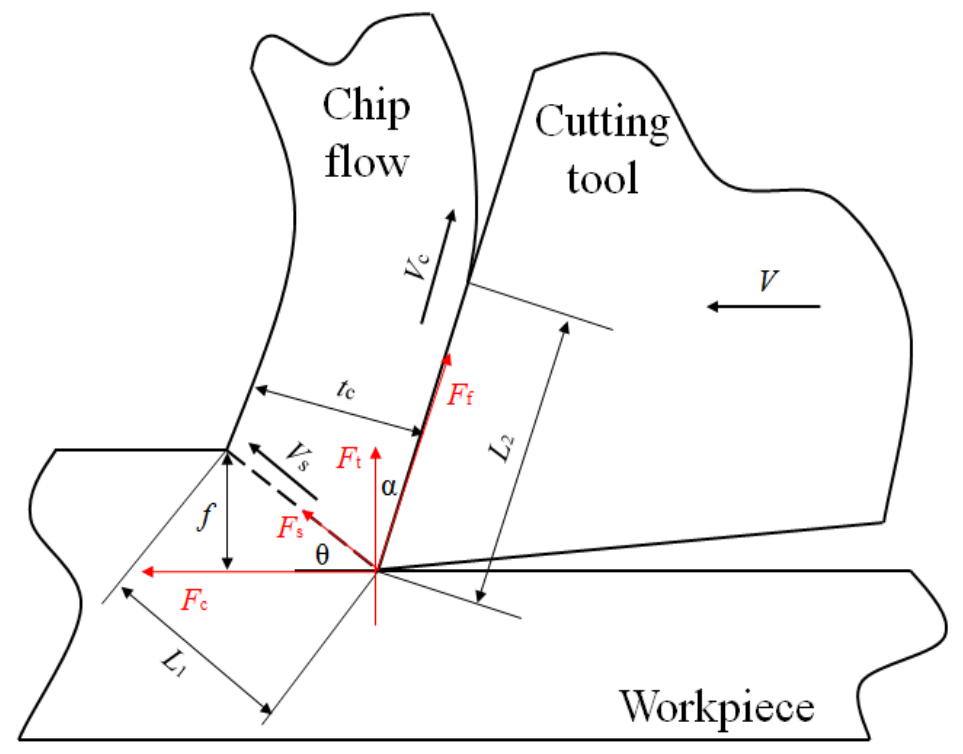

(b)

Fig. 6 (a) Heat generation and transfer in cutting processes (b) forces, velocities and geometric parameters in orthogonal cutting 
The flow chart in Fig. 7 shows the processes of calculation and validation. The heat flux q, which is the main input for CFD analysis, was calculated based on the analytical model with MatLab2016R by adopting the cutting parameters and cutting forces measured in the experiments. Combining the precalculated properties of three kinds of coolant, the heat transfer model could be solved to obtain the temperature distribution on the tool rake face. The calculated results were compared with the averages of measured temperature to validate the hybrid analytical-CFD model.

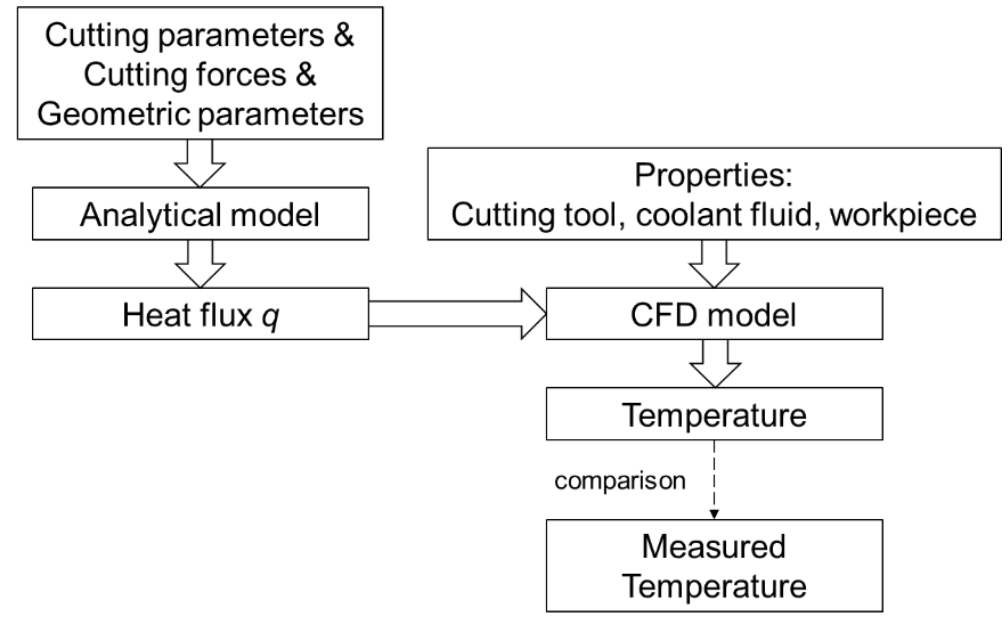

Fig. 7 Calculation and validation processes

\subsection{Calculated results}

Fig. 8 presents the temperature distribution on tool/chip interface within the range of 0 to $2 \mathrm{~mm}$ along the direction which is vertical to the cutting edge. To validate the model, the temperature at the position of the thermal couple was extracted to compare with the measured data (Table 5). The error was within $20 \%$, which means that the calculated results of temperature are acceptable. From the distribution of temperature, it was found that the temperature on tool rake faces reduced significantly at the position away from the cutting edge, and the addition of graphene oxide nanosheets did not affect the trend of temperature change. Furthermore, it can be found that the highest temperature at the tool/chip interface decreased significantly with the addition of graphene oxide nanosheets. Specifically, the maximum reduction in temperature at tool/interface can reach $100{ }^{\circ} \mathrm{C}$ when $0.5 \%$ w.t. graphene oxide was added 
into the coolant under the 1 bar coolant pressure although the temperature reduction at the measured position was only $30{ }^{\circ} \mathrm{C}$. Under the higher pressure, the largest temperature reduction was $80{ }^{\circ} \mathrm{C}$ when the cutting speed was $240 \mathrm{~m} / \mathrm{min}$.

Table 5 Calculated temperature and experimental data

\begin{tabular}{lc|ccc|ccc}
\hline Pressure & & \multicolumn{3}{|c|}{$1 \mathrm{bar}$} & \multicolumn{3}{c}{10 bar } \\
\hline Coolant & $\mathrm{V}(\mathrm{m} / \mathrm{min})$ & $\operatorname{Exp}\left({ }^{\circ} \mathrm{C}\right)$ & $\mathrm{Cal}\left({ }^{\circ} \mathrm{C}\right)$ & $\operatorname{Err}(\%)$ & $\operatorname{Exp}\left({ }^{\circ} \mathrm{C}\right)$ & $\mathrm{Cal}\left({ }^{\circ} \mathrm{C}\right)$ & $\operatorname{Err}(\%)$ \\
\hline \multirow{2}{*}{ Con_Cool } & 80 & 113 & 96 & 15 & 86 & 69 & 19.8 \\
& 160 & 140 & 128 & 8.6 & 112 & 99 & 11.6 \\
& 240 & 165 & 153 & 7.3 & 143 & 126 & 11.9 \\
GraO_0.1\% & 80 & 91 & 79 & 13.2 & 73 & 60 & 17.8 \\
& 160 & 125 & 109 & 12.8 & 99 & 87 & 12.1 \\
& 240 & 156 & 133 & 14.7 & 129 & 113 & 12.4 \\
GraO_0.5\% & 80 & 75 & 64 & 14.7 & 66 & 54 & 18.2 \\
& 160 & 107 & 89 & 16.8 & 93 & 79 & 15 \\
& 240 & 131 & 113 & 13.7 & 109 & 96 & 11.9 \\
\hline
\end{tabular}
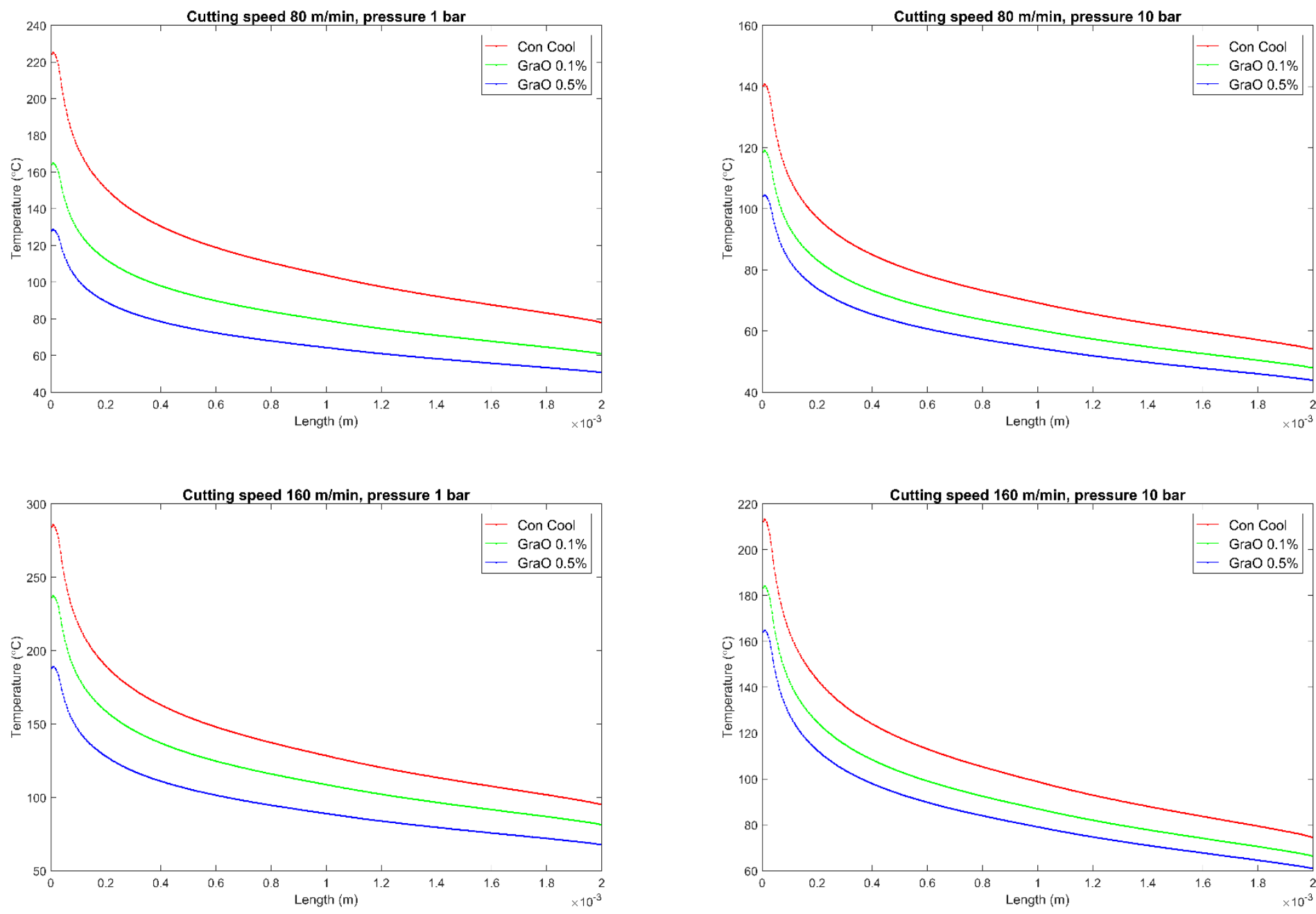

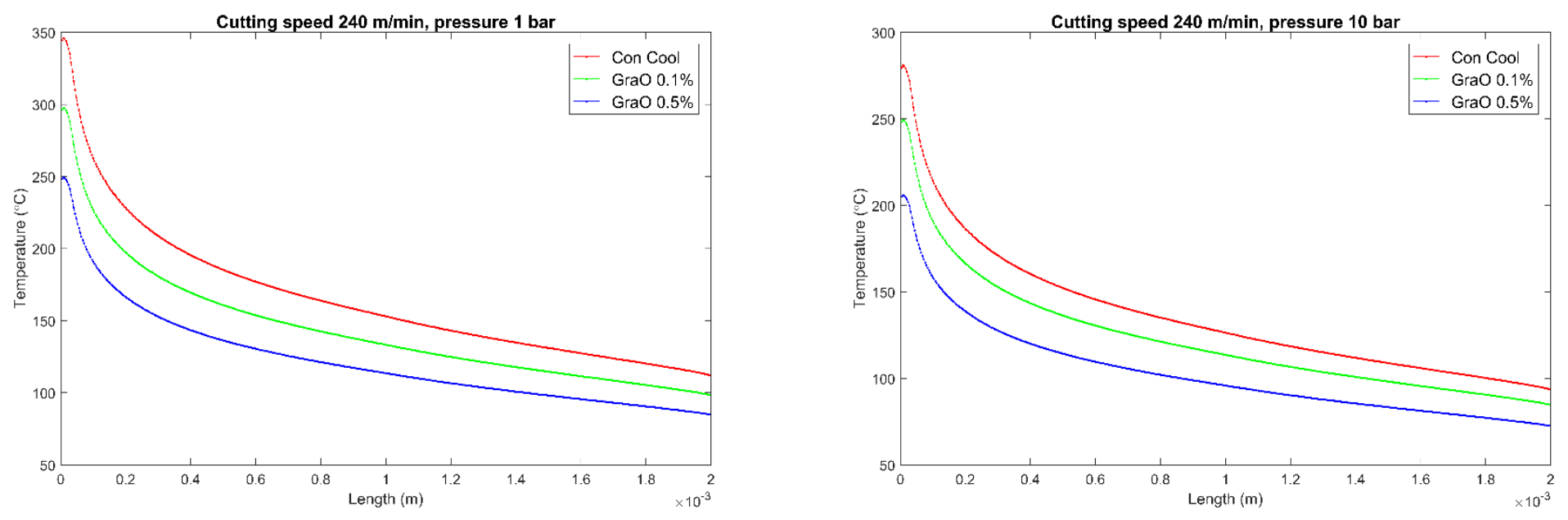

Fig. 8 Distribution of temperature on tool rake face at different cutting speeds and coolant pressure

To comprehensively investigate the cooling effect of different types of coolant, the ratio between the heat transferred to the cutting tool $(Q)$ and the heat transferred away by the coolant $\left(Q_{c}\right)$ within the range of 0 to $2 \mathrm{~mm}$ was calculated. In the following equation, $Q_{c}$ and $Q$ are the integration of the heat flux $q_{\text {int } 2}$ and $q_{\text {int } 1}$ within their corresponding regions, $L_{1}$ is the tool/chip contact length and $L_{2}$ is the length of the tool/coolant interface which equals to $\left(2-L_{1}\right) \mathrm{mm}$.

$$
R=\frac{Q_{c}}{Q}=\frac{\int_{0}^{L_{2}} q_{\text {int } 2}(l) d l}{\int_{0}^{L_{1}} q_{\text {int } 1}(l) d l}
$$

The calculation was conducted via the post processor of ANASYS R16.0, and the results are presented in Fig. 9. Different from the temperature which was influenced by the concentration of graphene oxide nanosheets, the ratios are all around $7 \%$ without any obvious distinction. This means that the addition of graphene oxide nanosheets does not increase the proportion of the heat transferred away by the cutting fluids. 

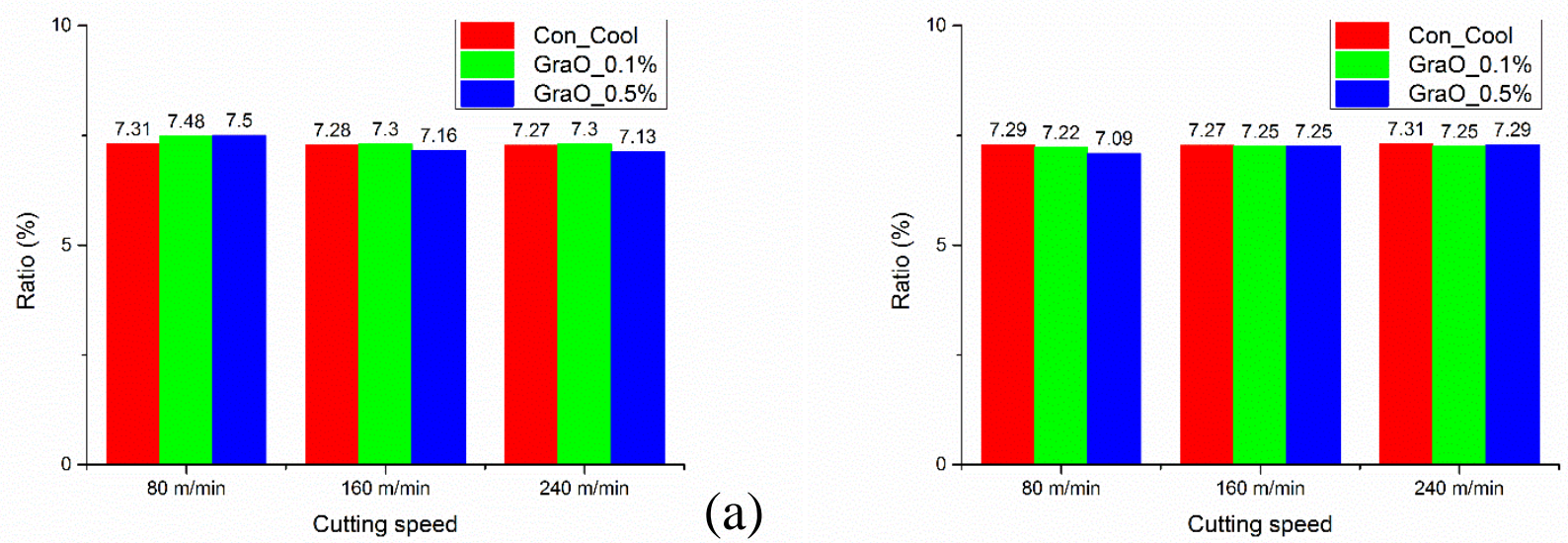

(b)

Fig. 9 The ratio of heat transferred away by the coolant at different cutting speeds (a) under 1 bar coolant pressure (b) under 10 bar coolant pressure

\subsection{Cooling mechanism}

It is believed that the cooling is the combined effects of different heat exchange processes including conduction, convection, evaporation and very little radiation (Yan et al., 2015). Among these types of heat transfer, the forced convection between the cutting tool and coolant is the dominant process that transfers the heat away (M. Daniel et al., 1996). The heat transfer coefficient describing the heat convection is the function of Nusselt number, Reynolds number and Prandtl number, which is presented in the following form when machining cylindrical workpieces (Holman, 1989),

$$
h=f(N u, \operatorname{Re}, \operatorname{Pr})=\frac{N_{u}(\operatorname{Re}, \operatorname{Pr}) K}{D}
$$

In this study, the fluid flow of coolant was considered as coolant jet ejected to the cutting tool and workpiece surface. With this flowing status, the Nusselt number $N_{u}$ could be determined with the values of Reynolds number, Prandtl number and the geometric parameter $G$ which is determined by the size of workpiece and the position of jet stagnation point (Martin, 1977):

$$
N_{u}=2 G R e^{0.5} \operatorname{Pr}^{0.42}\left(1+0.005 R e^{0.55}\right)^{0.5}
$$


For cylindrical workpieces, the Reynolds and Prandtl numbers are determined by the properties of the coolant liquid (thermal conductivity $K$, density $\rho$, specific heat $c_{p}$ and the dynamic viscosity $\mu$ ) and the size of workpiece material $(D)$, which are presented in the following equations (Holman, 1989):

Reynolds number $(R e): \quad R e=\frac{\rho V D}{\mu}$

Prandtl number $(P r): \quad \operatorname{Pr}=\frac{\mu c_{p}}{K}$

Based on Eqs. 16 to 19, it is found that the addition of graphene oxide nanosheets in coolant can hardly cause obvious changes to the status of heat convection $(h)$ as the difference in the properties of the three types of coolant is insignificant, and this is in consistence with the results presented in Fig. 9. As a result, the heat transferred away by the coolant was not the only reason contributing to the reduction of cutting temperature. It is well known that the heat in metal cutting processes is generated by the chip formation (shear deformation of workpiece in material primary deformation zone) and the tool/chip abrasion in the secondary deformation zone (Abukhshim et al., 2006). According to the calculated results in Table 5(a), obvious reduction in the amount of heat generated in the primary deformation zone was found with the increase of the concentration of graphene oxide nanosheets, leading to the decrease of temperature at tool/chip interface. The energy of shear deformation was strongly influenced by the shear force which is a component of the main cutting force. For this reason, it can be concluded that the reduction in cutting temperature was caused by the decrease of main cutting force due to the better lubrication of coolant with graphene oxide nanosheets, which will be introduced and discussed further in the following section.

\section{Analysis of lubrication effect}

\subsection{Calculation of friction force and friction coefficient}

In a cutting process, friction happens on the rake face and flank face due to the tool/chip and tool/workpiece abrasion. To investigate the lubrication effects on tool surfaces, the friction forces and friction coefficients on flank face and rake face were calculated when using different types of coolant. As presented in Fig. 10(a), to calculate the friction coefficients on different faces, the three components 
of the resultant cutting force $\mathrm{F}$ in the global coordinate system (XYZ) were firstly transferred into the oblique cutting system. In the new coordinate system, the $m$ axis and $n$ axis form the plane which is vertical to the cutting edge, and 1 axis is parallel to the cutting edge. Mathematically, the transformation of cutting forces from the global coordinate system to the oblique coordinate system was conducted by using the rotating matrix $[\mathrm{TM}]$, as presented in the following equations:

$$
\begin{gathered}
{\left[\begin{array}{c}
F_{l} \\
F_{m} \\
F_{n}
\end{array}\right]=[T M]\left[\begin{array}{l}
F_{x} \\
F_{y} \\
F_{z}
\end{array}\right]} \\
{[T M]=\left[\begin{array}{ccc}
\cos \theta_{n} & 0 & -\sin \theta_{n} \\
-\sin \theta_{s} \sin \theta_{n} & \cos \theta_{s} & -\sin \theta_{s} \cos \theta_{n} \\
\cos \theta_{s} \sin \theta_{0} & \sin \theta_{s} & \cos \theta_{s} \cos \theta_{n}
\end{array}\right]}
\end{gathered}
$$

Therefore, the three force components in the new coordinate system are calculated as follows:

$$
\left\{\begin{array}{l}
F_{1}=-F_{x} \sin \theta_{s} \sin \theta_{n}+F_{y} \cos \theta_{s}-F_{z} \sin \theta_{s} \cos \theta_{n} \\
F_{m}=F_{x} \cos \theta_{s} \sin \theta_{0}+F_{y} \sin \theta_{s}+F_{z} \cos \theta_{s} \cos \theta_{n} \\
F_{n}=F_{x} \cos \theta_{n}-F_{z} \sin \theta_{n}
\end{array}\right.
$$

As shown in Fig. 10(b), on the rake face, the friction force and the force normal to the rake face are equal to $F_{n}$ and $F_{m}$ respectively; as a result, the friction coefficient $\mu_{\text {rake }}$ is presented as follows:

$$
\mu_{\text {rake }}=\frac{f_{\text {rake }}}{N_{\text {rake }}}=\frac{F_{n}}{F_{m}}=\frac{F_{x} \cos \theta_{n}-F_{z} \sin \theta_{n}}{F_{x} \cos \theta_{s} \sin \theta_{0}+F_{y} \sin \theta_{s}+F_{z} \cos \theta_{s} \cos \theta_{n}}
$$

Similarly, the friction coefficient on flank face $\mu_{\text {flank }}$ can be calculated using the following equation:

$$
\mu_{\text {flank }}=\frac{f_{\text {flank }}}{N_{\text {flank }}}=\frac{F_{z} \cos \alpha_{n}-F_{x} \sin \alpha_{n}}{F_{z} \sin \alpha_{n}+F_{x} \cos \alpha_{n}}
$$




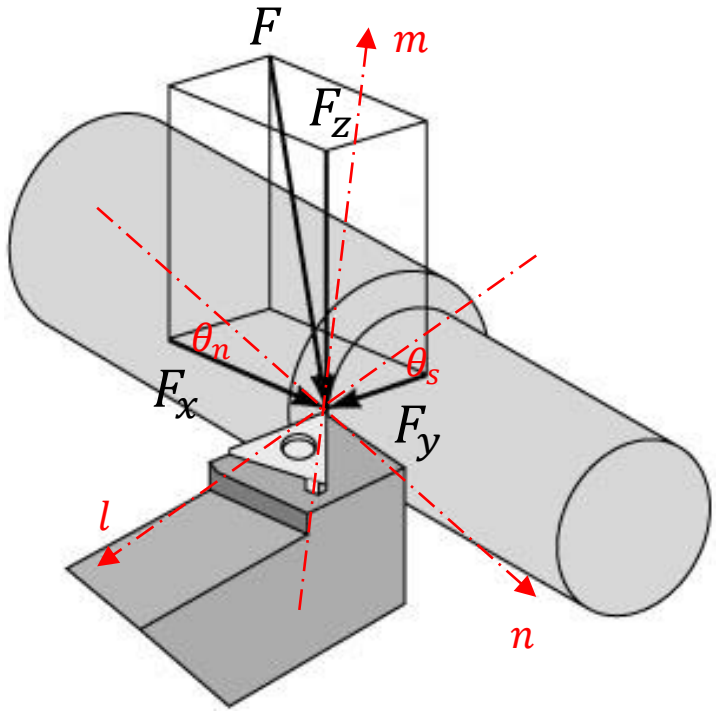

(a)

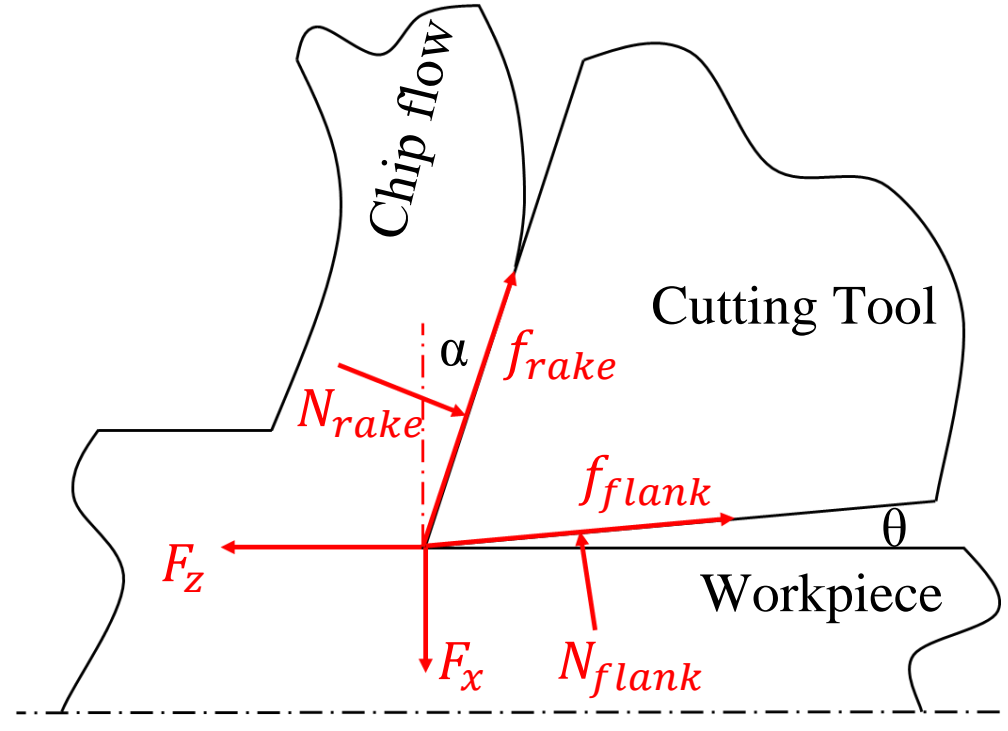

(b)

Fig. 10 (a) The global coordinate system and oblique cutting coordinate system (b) Forces in oblique plane

Fig. 11 shows the calculated friction forces and friction coefficients on flank faces under different cutting conditions. A reduction in friction force on flank face in the range of $25 \%$ to $50 \%$ could be found when the coolant with graphene nanosheet was applied. Specifically, the friction forces in using $\mathrm{GraO}_{0} 0.1 \%$ were reduced by $56 \mathrm{~N}, 32 \mathrm{~N}$ and $35 \mathrm{~N}$ compared with that of using conventional coolant when the pressure was 1 bar. The friction force was reduced by over $40 \%$ with the application of coolant GraO_0.5\% indicating better lubrication effect of the coolant with larger concentration of graphene oxide nanosheets. Under higher coolant pressure, the reduction in friction forces was significant as the application of high pressure coolant increased the amount of lubricating liquid at the friction area (da Silva et al., 2013). Also, friction force decreased with the increase of the concentration of graphene nanosheets in the coolant, and the percentage of reduction was around $35 \%$ to $50 \%$ at different cutting speeds and coolant pressures when GraO_0.5\% was applied. Similar to the change of friction force, friction coefficient decreased with the application of graphene nanosheets as well in the coolant under different cutting conditions (Fig. 11(c) and Fig. 11(d)). However, the concentration of graphene nanosheet did not cause significant difference in friction coefficient; the reduction was basically within 0.1 when the concentration of graphene oxide nanosheets was increased from $0.1 \%$ to $0.5 \%$. 

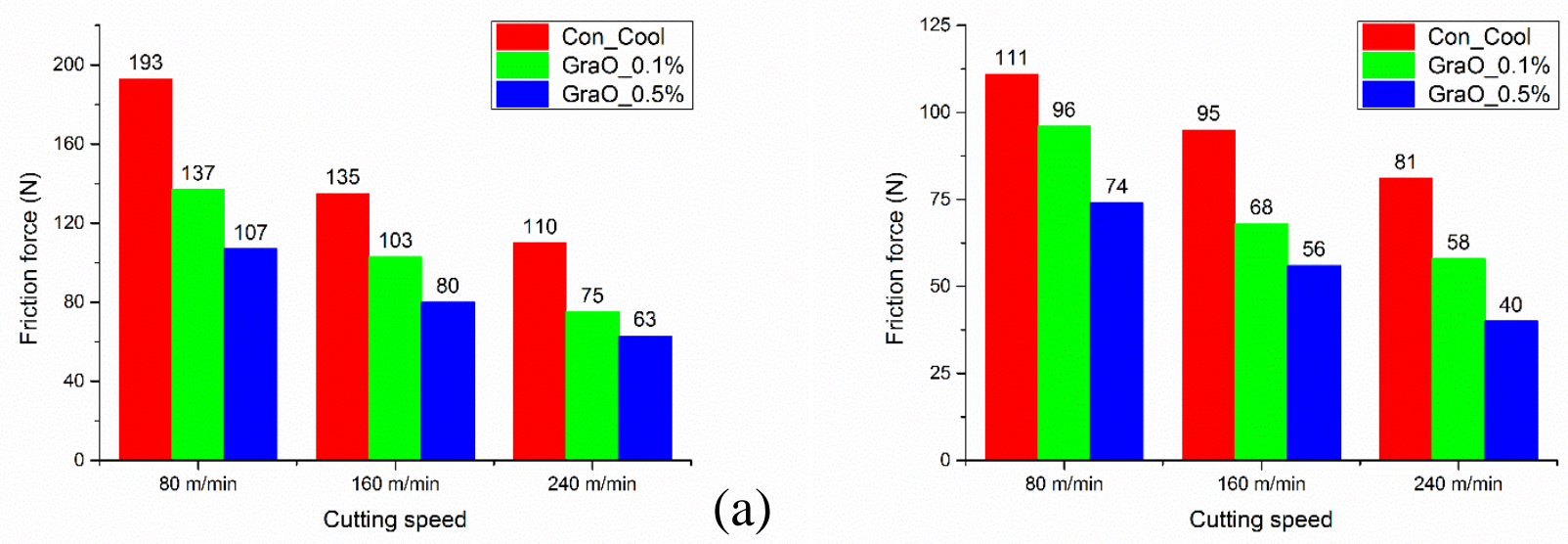

(b)

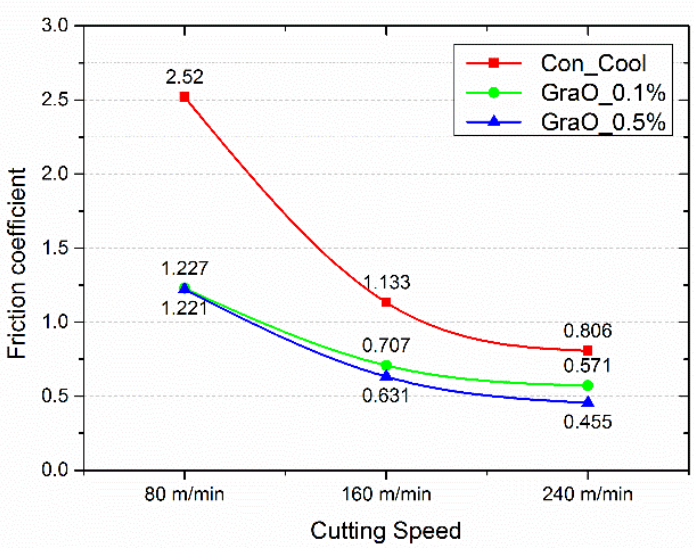

(c)

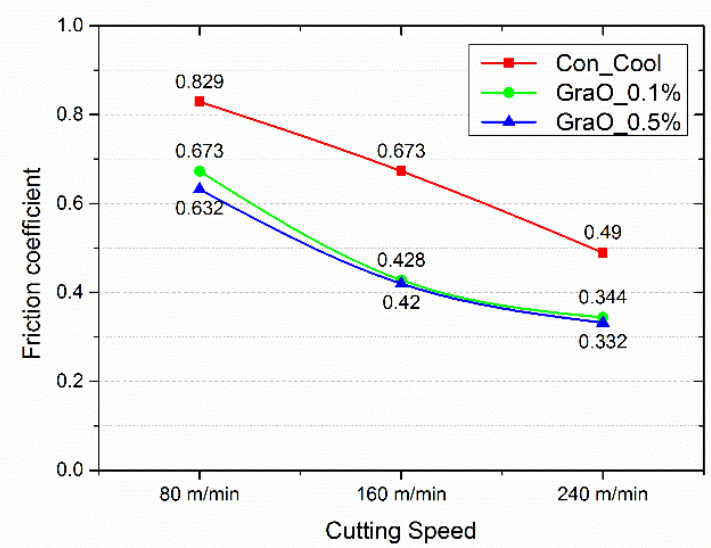

Fig. 11 Calculated frictional forces and friction coefficients on flank faces: (a) friction force at 1 bar coolant pressure (b) friction force at 10 bar coolant pressure (c) friction coefficient at 1 bar coolant pressure (d) friction coefficient at 10 bar coolant pressure

The change of friction force and friction coefficient on rake face was different from that on flank face (Fig. 12). Generally, both friction force and friction coefficient on flank face were relatively larger when the coolant with graphene oxide nanosheets was used. Under the 1 bar coolant pressure, the friction force increased with the increase of the concentration of graphene oxide nanosheets, however, the increment was within $10 \mathrm{~N}$. Also, the effect of coolant pressure on the friction forces of rake face was insignificant. The friction forces fluctuated around $50 \mathrm{~N}$ when using conventional coolant under the pressure of 10 bar, and it was around $45 \mathrm{~N}$ when using GraN-0.1 under both 1 bar and 10 bar pressures. The difference in friction forces caused by using three types of coolant was insignificant. As for the coefficient of friction on the rake face, the concentration of graphene oxide nanosheets did not cause too 
much difference at the low and normal cutting speeds. Smaller friction coefficients were found when conventional coolant was applied, and the reduction was $0.34(240 \mathrm{~m} / \mathrm{min}, 10 \mathrm{bar})$.

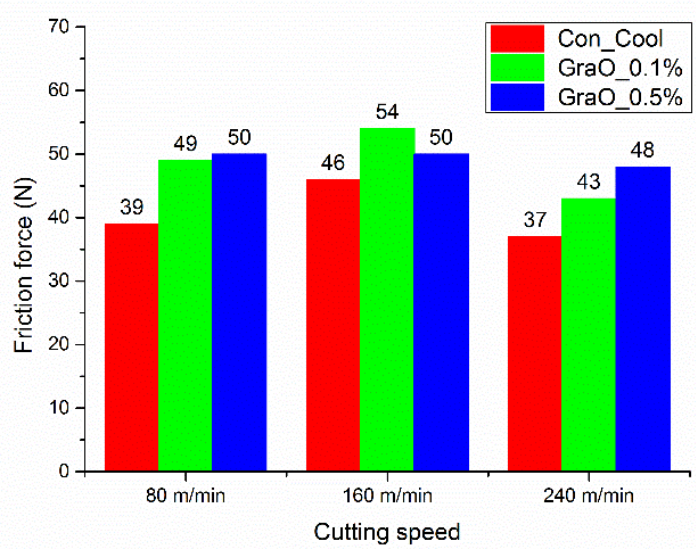

(a)

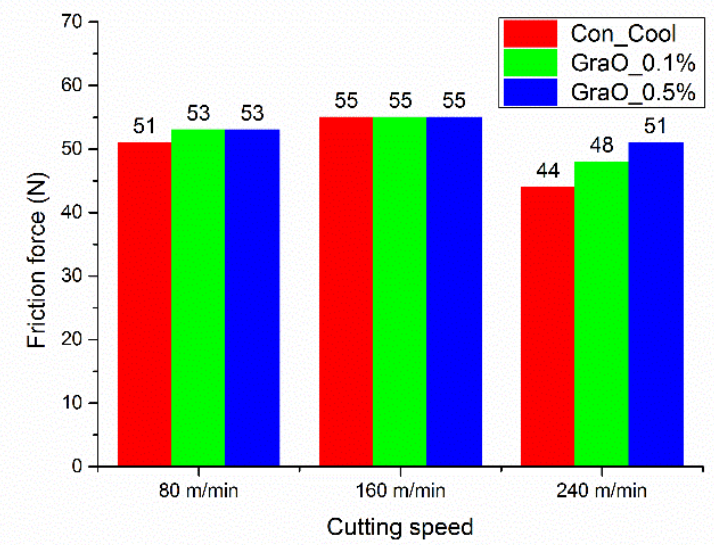

(b)

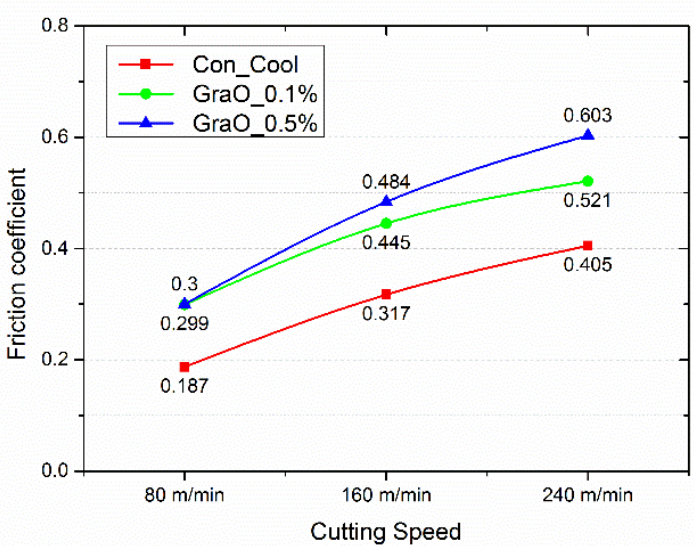

(c)

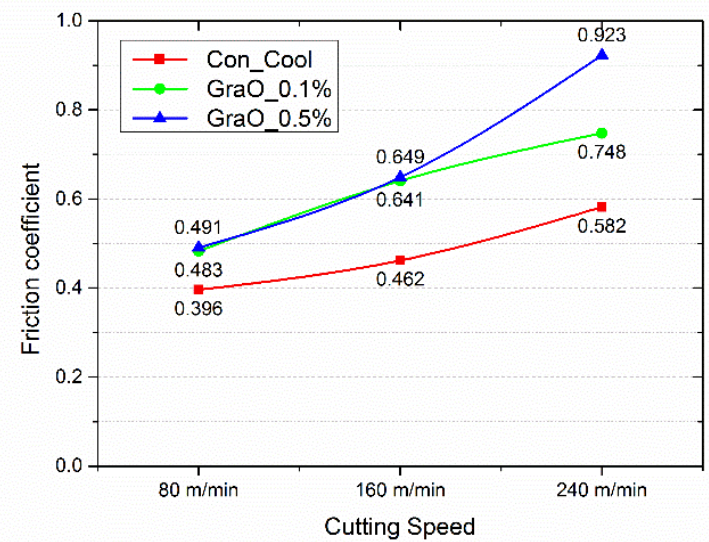

Fig. 12 Calculated frictional forces and friction coefficients on rake faces: (a) friction force under 1 bar coolant pressure (b) friction force under 10 bar coolant pressure (c) friction coefficient under 1 bar coolant pressure (d) friction coefficient under 10 bar coolant pressure

\subsection{Lubrication mechanism}

Based on the calculated results, it is obvious that the lubrication effects were not the same at the two interfaces (the tool/chip interface and the tool/workpiece interface). On the flank face, the significant reduction in friction forces when $\mathrm{GraO} \_0.1 \%$ and $\mathrm{GraO} \_0.5$ were used reflects that the addition of graphene improved the lubricating effects of coolant. However, on the rake face, the minor difference of friction force indicates that the addition of graphene oxide nanosheets did not reduce the tool/chip friction. To explain the difference of lubricating performance, the mechanism of lubrication on the two 
faces has to be analysed. Sharma et al. studied the lubrication mechanism of graphene nanosheets (Fig. 13) and concluded that graphene oxide nanosheets penetrated into the interfaces with the coolant liquid, and the laminate structure of graphene oxide was easily exfoliated by the shear forces forming a tribofilm at the sliding interfaces (Sharma et al., 2018). This conclusion was proved by the reduction on the development of flank wear with the application of coolant with graphene nanosheets when cutting speed was low (around $70 \mathrm{~m} / \mathrm{min}$ ). However, considering the characteristic of different sliding interfaces as well as the ability of penetration of the cooling fluid, according to the findings made by Childs (Childs, 2006), the liquid films cannot be formed along the tool/chip interface when cutting speed is high due to the intensive tool/chip contact and high cutting speeds. Moreover, the stress distribution on the rake face and flank face are different. As shown in Fig. 13(b), the normal stress on rake face $\sigma_{\text {rake }}$ was larger than the normal stress on flank face $\sigma_{\text {flank }}$ (Grzesik et al., 2014), which made the coolant jet hardly penetrate into the tool/chip interface. Therefore, the coolant can only reach to the end of tool/chip contact area due to the intensive interaction between tool rake face and chip back surface. This explained why the coolant pressure and concentration had minor influence on the friction force on rake faces. In comparison, the coolant can reach the tip position and results in better lubrication effects on flank face, which is reflected by the significant reduction in friction forces. When coolant pressure was increased or the coolant with higher concentration of graphene nanosheet was applied, the lubrication effect on flank face was significantly improved because both higher coolant pressure and larger concentration increased the amount of nanosheets in the lubricating process.

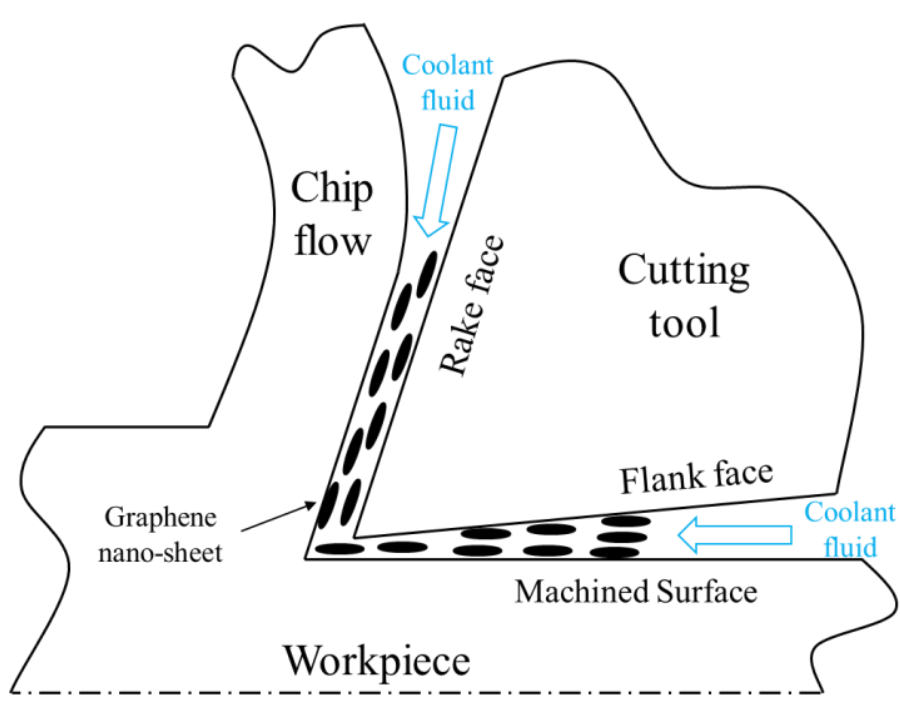

(a)

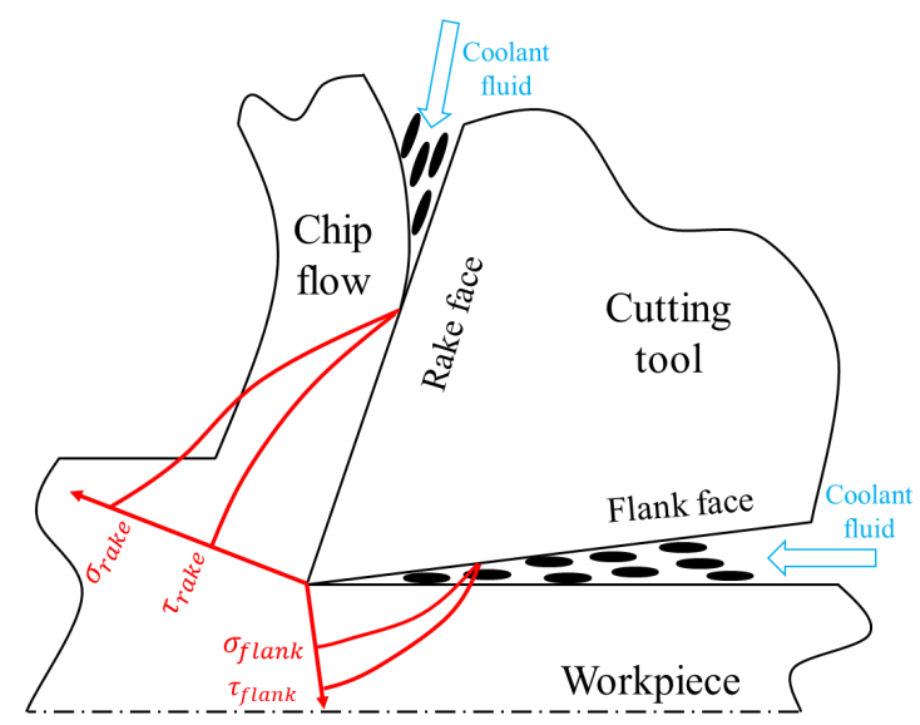

(b) 
Fig. 13 Lubrication mechanism (a) the proposed lubrication mechanism (Sharma et al., 2018) (b) the lubrication mechanism in this study

\section{Tool wear analysis}

Tool wear can directly reflect the effects of cooling and lubrication as the adhesive-abrasive process is strongly influenced by the cutting temperature and chip-tool-workpiece friction ( $\mathrm{Li}$ et al., 2017). As presented in Fig. 14, tool wear caused by abrasion and adhesion was found on the rake face and major flank face, the conditions of the flank wear and crater wear of the tools with different kinds of coolant were different.
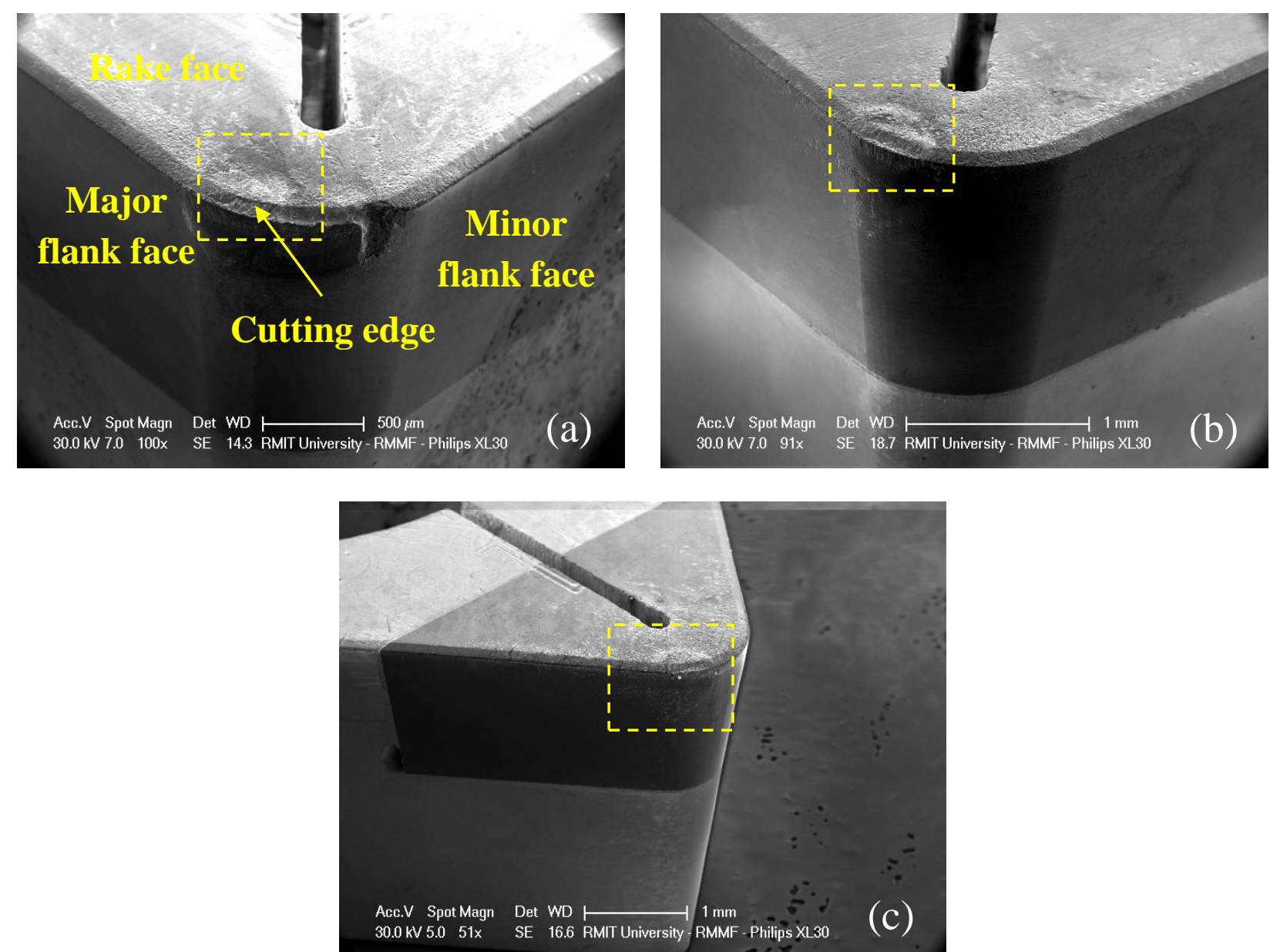

Fig. 14 Flank wear of the cutting tools under different coolant conditions (a) Con_Cool (b) GraO_0.1\% (c) GraO_0.5\% 
Flank wear is the material loss on the flank face mainly caused by the tool/workpiece abrasion. The condition of flank wear was investigated by analysing the width of flank wear (VB) and the roughness of machined surface $(\mathrm{Ra})$, both of which were measured by the Alicona microscope (Measurement Suite). The VBs of the three tools were $96 \mu \mathrm{m}, 81 \mu \mathrm{m}$ and $78 \mu \mathrm{m}$ respectively when conventional coolant and coolants with graphene nanosheets of different concentrations were applied (Fig. 14). The reduction of $15 \%$ and $20 \%$ in VB proved the better lubrication ability of coolants with graphene oxide nanosheet suspension, which is in consistence with the reduction of friction force and friction coefficient in Section 4.1. Also, the lubrication condition when using different types of coolant was reflected by the roughness of machined surface $(\mathrm{Ra})$. As shown in Fig. 15, values of Ra were smaller with the using of GraO_0.1\% and $\mathrm{GraO} \_0.5 \%$, this was in consistent with the experimental results on nanofluids of graphite-based nanoparticles (e.g. (Li et al., 2019)). The Ras of the surface with Con_Cool were generally over $120 \mathrm{~nm}$ under different pressures. In contrast, the surface roughness of $\mathrm{GraO} \_0.1 \%$ and $\mathrm{GraO} \_0.5 \%$ were below $120 \mathrm{~nm}$ under different cutting conditions and this that the tool/workpiece abrasion was reduced with the addition of graphene nanosheet. Especially, when using $\mathrm{GraO}_{-} 0.5 \%$, the largest roughness was merely higher than $100 \mathrm{~nm}$, and the reduction on Ra was 30-60 nm (over 30\%) compared with that of Con_Cool. This is similar to the findings made by Singh et al. (Singh et al., 2018) because more lattice structured graphene were conveyed to the interface between flank face and workpiece surface, lubricating the tool/workpiece abrasion during the cutting processes.

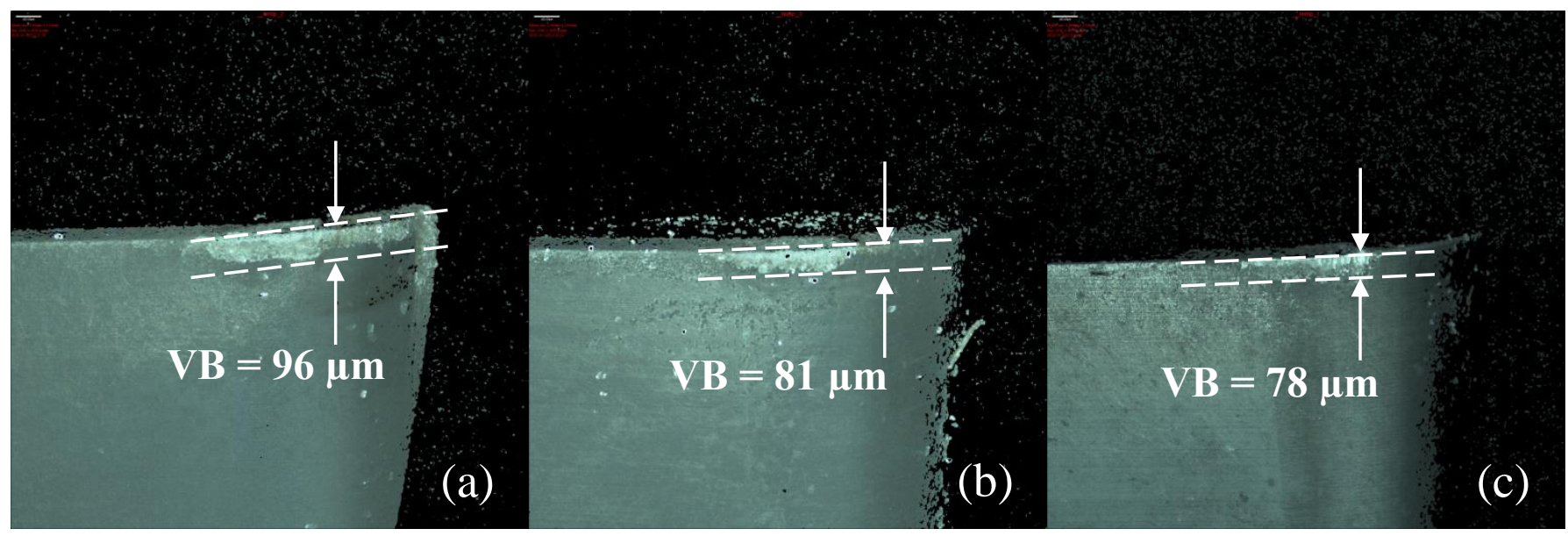

Fig. 15 Flank wear of the cutting tools under different coolant conditions (a) Con_Cool (b) GraO_0.1\% (c) GraO_0.5\% 

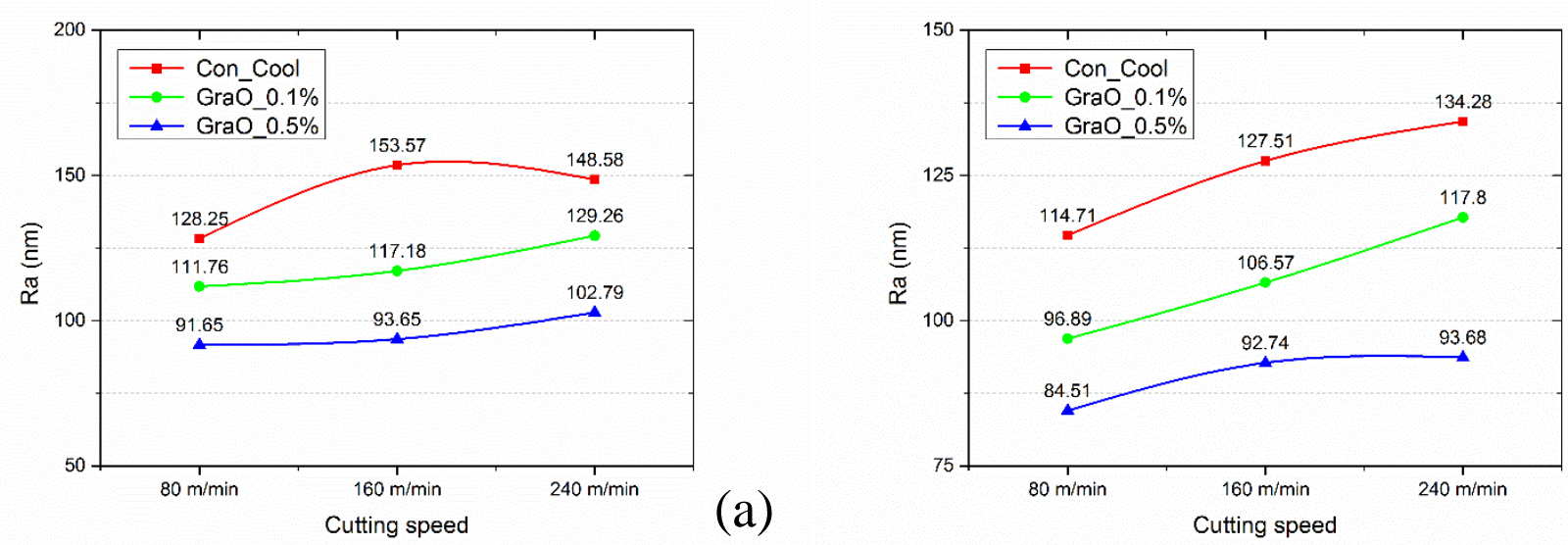

Fig. 16 Roughness of machined surface under different cutting conditions (a) 1-bar coolant pressure (b) 10-bar coolant pressure

Crater wear is stimulated by the high stress and temperature at tool/chip interface resulting in the loss of tool material and the adhesion of workpiece material on the rake face (Li et al., 2018). The worn areas on rake faces were examined by Alicona (Measurement Suite), as shown in Fig. 16, it was found that the size of the worn area was reduced with the increase of the concentration of graphene oxide nanosheets. The depth of the crater $\left(K_{c}\right)$ and the tool/chip contact length $\left(L_{t c}\right)$ were two factors describing the condition of tool wear on rake face. Based on established models, $K_{C}$ was the function of temperature (Huang and Dawson, 2005) and $L_{t c}$ mainly reflected the status of tool/chip abrasion (Bahi et al., 2012). In our experiments, it was found that $K_{c}$ decreased with the addition of graphene oxide nanosheet in coolants, which indicated the reduction of the temperature at tool/chip interface. The tool/chip contact lengths $\left(L_{t c}\right)$ of the three tools are similar (around $\left.180 \mu \mathrm{m}\right)$. This indicates that the influence of graphene oxide nanosheet on abrasion at tool/chip interface was insignificant because the graphene oxide nanosheets could hardly penetrate into the interface due to the intensive tool/chip contact. 


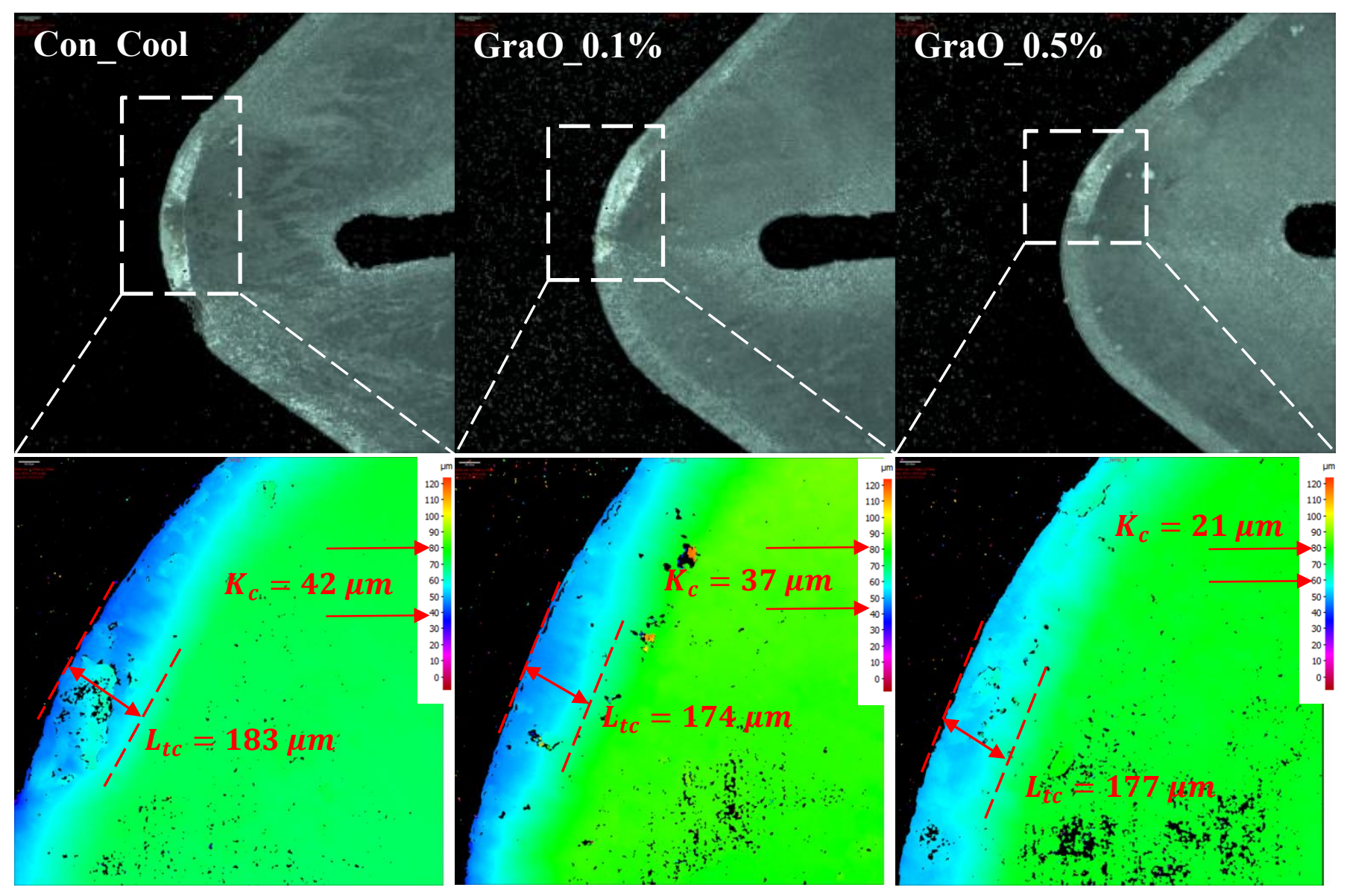

Fig. 17 Crater wear of the cutting tools under different coolant conditions

Fig. 17 shows the morphological characters of worn area when using different types of coolant; defects caused by the adhesive-abrasive process were found on rake faces of tools. BUE were found on all three tools because of the blunt cutting edges. The abrasive areas within the worn areas show that the tool/chip abrasion on the three faces was severe. Surface near the tool/chip contact area was burned, which means the temperature of chip flow when using conventional coolant was much higher than that of using the coolant with graphene oxide nanosheets. Also, the adhesion layer was found near the cutting edge of the tool with the coolant GraO_0.5\%. In contrast, the adhesion layer on the other tools was not obvious. Because of the higher temperature at the tool/chip interface, the removal of the adhesion layer as well as the part of adhered material by the chip flow became easier. 

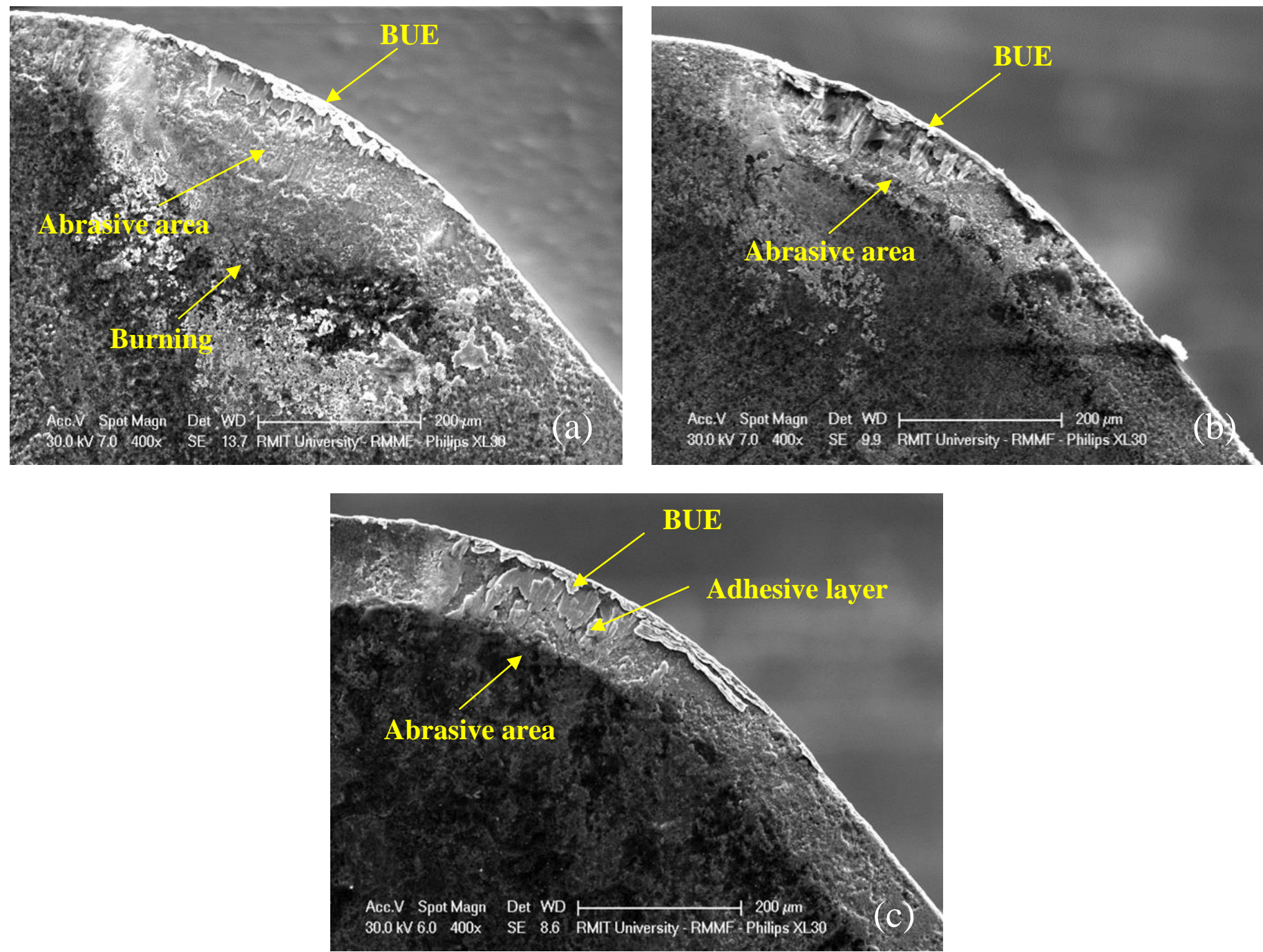

Fig. 18 Worn areas of tools under different types of coolant: (a) Con_Cool (b) $\mathrm{GraO} \_0.1 \%$ (c) GraO_0.5 


\section{Conclusion}

The cooling and lubrication effects of three types of metalworking fluid were investigated: Con_Cool, GraO_0.1\%, and GraO_0.5\%. Experiments of turning Ti6A14V were conducted under different cutting conditions, and a new CFD-analytical model was developed to analyse the distribution of cutting temperature. Friction force and friction coefficient were calculated to quantify the lubrication effect at the tool/chip interface and the tool/workpiece interface. The worn areas on tool surface were examined to investigate the cooling and lubrication mechanisms. By analysing the change of cutting temperature, friction force, friction coefficient and the morphological characters of tool wear, the effects of cooling and lubrication at different interfaces were discovered.

The cutting temperature measured in experiments was reduced when the coolants of GraO_0.1\% and GraO_0.5\% were applied. Also, the temperature at tool/chip interface decreased significantly with the increase of the concentration of graphene oxide nanosheets in the fluids. Near the tool/chip interface, $7 \%$ of the total heat was transferred away by the heat convection between tool surface and the coolant, and the influence of the addition of graphene oxide nanosheets on heat convection process was limited.

Both friction force and friction coefficient on flank face were reduced significantly with the addition of graphene oxide nanosheets because the smaller normal pressure made the nanosheets easier to penetrate into the tool/workpiece interface reducing the tool/workpiece abrasion. On tool rake face, the change of friction force under different types of cooling conditions were insignificant as the coolant can hardly reach the tool/chip interface due to the intensive tool/chip interaction.

Morphological characters on the worn areas reflect the cooling and lubrication effects of the three coolants. The improved lubrication ability and cooling effect of coolant when using the graphene oxide nanosheets were shown by the reduced VB and $K_{c}$ respectively. However, similar values of $L_{t c}$ proved the minor influence of graphene oxide nanosheet on abrasion at tool/chip interface.

\section{Acknowledgement:}


The paper is partially supported by the Australian Research Council (DP180100762). The authors acknowledge the facilities, and the scientific and technical assistance of the RMIT Microscopy \& Microanalysis Facility (RMMF), a linked laboratory of Microscopy Australia. 


\section{Reference}

Abukhshim, N.A., Mativenga, P.T., Sheikh, M.A., 2006. Heat generation and temperature prediction in metal cutting: A review and implications for high speed machining. International Journal of Machine Tools and Manufacture 46, 782-800.

Ahmed, L.S., Kumar, M.P., 2016. Cryogenic drilling of Ti-6Al-4V alloy under liquid nitrogen cooling. Materials and Manufacturing Processes 31, 951-959.

Amin, A.K.M.N., Ismail, A.F., Nor Khairusshima, M.K., 2007. Effectiveness of uncoated WCCo and PCD inserts in end milling of titanium alloy-Ti-6Al-4V. Journal of Materials Processing Technology 192-193, 147-158.

Bahi, S., Nouari, M., Moufki, A., Mansori, M.E., Molinari, A., 2012. Hybrid modelling of sliding-sticking zones at the tool-chip interface under dry machining and tool wear analysis. Wear 286-287, 45-54.

Behroyan, I., Vanaki, S.M., Ganesan, P., Saidur, R., 2016. A comprehensive comparison of various CFD models for convective heat transfer of $\mathrm{Al} 2 \mathrm{O} 3$ nanofluid inside a heated tube. International Communications in Heat and Mass Transfer 70, 27-37.

Chandrasekar, M., Suresh, S., Senthilkumar, T., 2012. Mechanisms proposed through experimental investigations on thermophysical properties and forced convective heat transfer characteristics of various nanofluids - A review. Renewable and Sustainable Energy Reviews 16, 3917-3938.

Childs, T.H.C., 2006. Friction modelling in metal cutting. Wear 260, 310-318.

Choi, S.U.S., 2009. Nanofluids: From Vision to Reality Through Research. Journal of Heat Transfer 131, 033106-033106-033109.

da Silva, R.B., Machado, Á.R., Ezugwu, E.O., Bonney, J., Sales, W.F., 2013. Tool life and wear mechanisms in high speed machining of Ti-6Al-4V alloy with PCD tools under various coolant pressures. Journal of Materials Processing Technology 213, 1459-1464.

Debnath, S., Reddy, M.M., Yi, Q.S., 2014. Environmental friendly cutting fluids and cooling techniques in machining: a review. Journal of Cleaner Production 83, 33-47.

Derek, K., 2014, How “Nano-Onions" Help Improve Cutting Performance, https://www.mmsonline.com/articles/how-nano-onions-help-improve-cutting-performance.

Dhananchezian, M., Kumar, M.P., 2011. Cryogenic turning of the Ti-6Al-4V alloy with modified cutting tool inserts. Cryogenics 51, 34-40.

Egana, A., Rech, J., Arrazola, P., 2012. Characterization of friction and heat partition coefficients during machining of a TiAl6V4 titanium alloy and a cemented carbide. Tribology Transactions 55, 665-676.

El Baradie, M.A., 1996a. Cutting fluids: Part I. Characterisation. Journal of Materials Processing Technology 56, 786-797.

El Baradie, M.A., 1996b. Cutting fluids: Part II. Recycling and clean machining. Journal of Materials Processing Technology 56, 798-806.

Gajrani, K.K., Suvin, P.S., Kailas, S.V., Mamilla, R.S., 2019. Thermal, rheological, wettability and hard machining performance of MoS2 and $\mathrm{CaF} 2$ based minimum quantity hybrid nanogreen cutting fluids. Journal of Materials Processing Technology 266, 125-139.

Grzesik, W., Rech, J., Żak, K., 2014. Determination of friction in metal cutting with tool wear and flank face effects. Wear 317, 8-16. 
Hadadian, M., Goharshadi, E.K., Youssefi, A., 2014. Electrical conductivity, thermal conductivity, and rheological properties of graphene oxide-based nanofluids. Journal of Nanoparticle Research 16, 2788.

Holman, J.P., 1989. Heat transfer. McGraw-Hill.

Huang, H., Tu, J., Gan, L., Li, C., 2006. An investigation on tribological properties of graphite nanosheets as oil additive. Wear 261, 140-144.

Huang, Y., Dawson, T.G., 2005. Tool crater wear depth modeling in CBN hard turning. Wear 258, 1455-1461.

Jayal, A.D., Badurdeen, F., Dillon, O.W., Jawahir, I.S., 2010. Sustainable manufacturing: Modeling and optimization challenges at the product, process and system levels. CIRP Journal of Manufacturing Science and Technology 2, 144-152.

Komanduri, R., Hou, Z.B., 2001. Thermal modeling of the metal cutting process - Part II: temperature rise distribution due to frictional heat source at the tool-chip interface. International Journal of Mechanical Sciences 43, 57-88.

Leppert, T., Peng, R.L., 2012. Residual stresses in surface layer after dry and MQL turning of AISI 316L steel. Production Engineering 6, 367-374.

Li, G., Yi, S., Sun, S., Ding, S., 2017. Wear mechanisms and performance of abrasively ground polycrystalline diamond tools of different diamond grains in machining titanium alloy. Journal of Manufacturing Processes 29, 320-331.

Li, G., Yi, S., Wen, C., Ding, S., 2018. Wear Mechanism and Modeling of Tribological Behavior of Polycrystalline Diamond Tools When Cutting Ti6A14V. Journal of Manufacturing Science and Engineering 140, 121011-121011-121015.

Li, H., Chen, L., Zhang, Y., Ji, X., Chen, S., Song, H., Li, C., Tang, H., 2014. Synthesis of MoSe2/Reduced graphene oxide composites with improved tribological properties for oil based additives. Crystal Research and Technology 49, 204-211.

Li, M., Yu, T., Yang, L., Li, H., Zhang, R., Wang, W., 2019. Parameter optimization during minimum quantity lubrication milling of TC4 alloy with graphene-dispersed vegetable-oilbased cutting fluid. Journal of Cleaner Production 209, 1508-1522.

Lv, T., Huang, S., Liu, E., Ma, Y., Xu, X., 2018. Tribological and machining characteristics of an electrostatic minimum quantity lubrication (EMQL) technology using graphene nanolubricants as cutting fluids. Journal of Manufacturing Processes 34, 225-237.

M. Daniel, C., Rao, K.V.C., W. Olson, W., Sutherland, J., 1996. Effect of cutting fluid properties and application variables on heat transfer in turning and boring operations.

Martin, H., 1977. Heat and Mass Transfer between Impinging Gas Jets and Solid Surfaces, In: Hartnett, J.P., Irvine, T.F. (Eds.), Advances in Heat Transfer. Elsevier, pp. 1-60.

Nam, J.S., Lee, P.-H., Lee, S.W., 2011. Experimental characterization of micro-drilling process using nanofluid minimum quantity lubrication. International Journal of Machine Tools and Manufacture 51, 649-652.

Oosthuizen, G., Akdogan, G., Dimitrov, D., Treunicht, N., 2010. A review of the machinability of titanium alloys. R \& D Journal of the South African Institution of Mechanical Engineering $26,43-52$.

Phuoc, T.X., Massoudi, M., Chen, R.-H., 2011. Viscosity and thermal conductivity of nanofluids containing multi-walled carbon nanotubes stabilized by chitosan. International Journal of Thermal Sciences 50, 12-18.

Prabhu, S., Vinayagam, B.K., 2011. Nano surface generation of grinding process using carbon nano tubes. Sadhana 35, 747. 
Samuel, J., Rafiee, J., Dhiman, P., Yu, Z.-Z., Koratkar, N., 2011. Graphene colloidal suspensions as high performance semi-synthetic metal-working fluids. The Journal of Physical Chemistry C 115, 3410-3415.

Sharma, A.K., Tiwari, A.K., Dixit, A.R., 2015. Progress of nanofluid application in machining: a review. Materials and Manufacturing Processes 30, 813-828.

Sharma, A.K., Tiwari, A.K., Dixit, A.R., 2016. Effects of Minimum Quantity Lubrication (MQL) in machining processes using conventional and nanofluid based cutting fluids: A comprehensive review. Journal of cleaner production 127, 1-18.

Sharma, A.K., Tiwari, A.K., Dixit, A.R., Singh, R.K., Singh, M., 2018. Novel uses of alumina/graphene hybrid nanoparticle additives for improved tribological properties of lubricant in turning operation. Tribology International 119, 99-111.

Sidik, N.A.C., Samion, S., Ghaderian, J., Yazid, M.N.A.W.M., 2017. Recent progress on the application of nanofluids in minimum quantity lubrication machining: A review. International Journal of Heat and Mass Transfer 108, 79-89.

Singh, R.k., Sharma, A.K., Bishwajeet, Mandal, V., Gaurav, K., Nag, A., Kumar, A., Dixit, A.R., Mandal, A., Kumar Das, A., 2018. Influence of graphene-based nanofluid with minimum quantity lubrication on surface roughness and cutting temperature in turning operation. Materials Today: Proceedings 5, 24578-24586.

Smith, P.J., Chu, B., Singh, E., Chow, P., Samuel, J., Koratkar, N., 2015. Graphene oxide colloidal suspensions mitigate carbon diffusion during diamond turning of steel. Journal of Manufacturing Processes 17, 41-47.

Sridharan, U., Malkin, S., 2009. Effect of minimum quantity lubrication (MQL) with nanofluids on grinding behavior and thermal distortion, Transactions of the North American Manufacturing Research Institution of SME, pp. 629-636.

Stankovich, S., Dikin, D.A., Piner, R.D., Kohlhaas, K.A., Kleinhammes, A., Jia, Y., Wu, Y., Nguyen, S.T., Ruoff, R.S., 2007. Synthesis of graphene-based nanosheets via chemical reduction of exfoliated graphite oxide. carbon 45, 1558-1565.

Su, Y., He, N., Li, L., Iqbal, A., Xiao, M.H., Xu, S., Qiu, B.G., 2007. Refrigerated cooling air cutting of difficult-to-cut materials. International Journal of Machine Tools and Manufacture 47, 927-933.

Taylor, R., Coulombe, S., Otanicar, T., Phelan, P., Gunawan, A., Lv, W., Rosengarten, G., Prasher, R., Tyagi, H., 2013. Small particles, big impacts: a review of the diverse applications of nanofluids. Journal of Applied Physics 113, 1.

Tu, J., Yeoh, G.-H., Liu, C., 2018. Computational fluid dynamics: a practical approach. Butterworth-Heinemann.

Vajjha, R.S., Das, D.K., 2009. Experimental determination of thermal conductivity of three nanofluids and development of new correlations. International Journal of Heat and Mass Transfer 52, 4675-4682.

Yan, P., Rong, Y., Wang, G., 2015. The effect of cutting fluids applied in metal cutting process. Proceedings of the Institution of Mechanical Engineers, Part B: Journal of Engineering Manufacture 230, 19-37.

Yan, S., Zhu, D., Zhuang, K., Zhang, X., Ding, H., 2014. Modeling and analysis of coated tool temperature variation in dry milling of Inconel 718 turbine blade considering flank wear effect. Journal of Materials Processing Technology 214, 2985-3001.

Yildiz, Y., Nalbant, M., 2008. A review of cryogenic cooling in machining processes. International Journal of Machine Tools and Manufacture 48, 947-964. 
Zhang, Y., Li, C., Jia, D., Li, B., Wang, Y., Yang, M., Hou, Y., Zhang, X., 2016. Experimental study on the effect of nanoparticle concentration on the lubricating property of nanofluids for MQL grinding of Ni-based alloy. Journal of Materials Processing Technology 232, 100-115.

Zhou, S.-Q., Ni, R., 2008. Measurement of the specific heat capacity of water-based Al 2 O 3 nanofluid. Applied Physics Letters 92, 093123.

Zhu, Y., Murali, S., Cai, W., Li, X., Suk, J.W., Potts, J.R., Ruoff, R.S., 2010. Graphene and graphene oxide: synthesis, properties, and applications. Advanced materials 22, 3906-3924. 
Table 1 Property and composition of ROCOL Ultracut Clear

\begin{tabular}{lllll}
\hline Density $(\mathrm{g} / \mathrm{cm} 3)$ & Mineral oil & Natural oil & Water & Others \\
\hline 0.95 & $20 \%$ & $20 \%$ & $60 \%$ & $<1 \%$ \\
\hline
\end{tabular}

Table 2 Properties of Sigma Aldrich graphene oxide nanosheets

\begin{tabular}{lllll}
\hline Purity & $\begin{array}{l}\text { Thickness } \\
(\mathrm{nm})\end{array}$ & Diameter $(\mathrm{nm})$ & Layers & $\begin{array}{l}\text { Specific surface } \\
\text { area }\end{array}$ \\
\hline $99 \%$ & $1-1.77$ & $0.5-5$ & $1-5$ & $300-450$ \\
\hline
\end{tabular}

Table 3 Physical and thermal properties of different kinds of coolant

\begin{tabular}{lccc}
\hline Coolant & Density & $\begin{array}{c}\text { Thermal } \\
\text { conductivity } \\
\left(W \cdot m^{-1} K^{-1}\right)\end{array}$ & $\begin{array}{c}\text { Specific heat } \\
\left(J \cdot g^{-1}{ }^{\circ} \mathrm{C}^{-1}\right)\end{array}$ \\
\hline Con_Cool & 0.94 & 0.249 & 3.24 \\
GraO_0.1\% & 0.94 & 0.253 & 3.24 \\
GraO_0.5\% & 0.94 & 0.267 & 3.24 \\
\hline
\end{tabular}

Table $4 Q_{\text {primary }}$ and $Q_{\text {secondary }}(\mathrm{W})$ under different cooling conditions

\begin{tabular}{|c|c|c|c|c|c|c|}
\hline \multicolumn{7}{|l|}{$Q_{\text {primary }}$} \\
\hline $\begin{array}{l}\text { Coolant } \\
\text { pressure }\end{array}$ & \multicolumn{3}{|c|}{$1 \mathrm{bar}$} & \multicolumn{3}{|c|}{$10 \mathrm{bar}$} \\
\hline Cutting speed & $\begin{array}{c}80 \\
\mathrm{~m} / \mathrm{min}\end{array}$ & $\begin{array}{c}160 \\
\mathrm{~m} / \mathrm{min}\end{array}$ & $\begin{array}{c}240 \\
\mathrm{~m} / \mathrm{min}\end{array}$ & $\begin{array}{c}80 \\
\mathrm{~m} / \mathrm{min}\end{array}$ & $\begin{array}{c}160 \\
\mathrm{~m} / \mathrm{min}\end{array}$ & $\begin{array}{c}240 \\
\mathrm{~m} / \mathrm{min}\end{array}$ \\
\hline Con_Cool & 233.53 & 330.17 & 388.41 & 134.31 & 231.36 & 268.62 \\
\hline GraO_0.1\% & 163.35 & 248.23 & 290.4 & 114.95 & 163.88 & 203.28 \\
\hline GraO_0.5\% & 133.1 & 180.75 & 228.69 & 98.01 & 139.78 & 145.2 \\
\hline \multicolumn{7}{|l|}{$Q_{\text {secondary }}$} \\
\hline $\begin{array}{l}\text { Coolant } \\
\text { pressure }\end{array}$ & & 1 bar & & & 10 bar & \\
\hline Cutting speed & $\begin{array}{c}80 \\
\mathrm{~m} / \mathrm{min}\end{array}$ & $\begin{array}{c}160 \\
\mathrm{~m} / \mathrm{min}\end{array}$ & $\begin{array}{c}240 \\
\mathrm{~m} / \mathrm{min}\end{array}$ & $\begin{array}{c}80 \\
\mathrm{~m} / \mathrm{min}\end{array}$ & $\begin{array}{c}160 \\
\mathrm{~m} / \mathrm{min}\end{array}$ & $\begin{array}{c}240 \\
\mathrm{~m} / \mathrm{min}\end{array}$ \\
\hline Con_Cool & 51.87 & 130.34 & 200 & 67.83 & 140.98 & 212 \\
\hline GraO_0.1\% & 61.18 & 143.64 & 200 & 73.15 & 146.3 & 220 \\
\hline GraO_0.5\% & 49.21 & 114.38 & 192 & 58.52 & 127.68 & 204 \\
\hline
\end{tabular}

Table 5 Calculated temperature and experimental data

\begin{tabular}{lc|ccc|ccc}
\hline Pressure & & \multicolumn{3}{|c|}{$1 \mathrm{bar}$} & \multicolumn{3}{c}{$10 \mathrm{bar}$} \\
\hline \multirow{2}{*}{ Coolant } & $\mathrm{V}(\mathrm{m} / \mathrm{min})$ & $\operatorname{Exp}\left({ }^{\circ} \mathrm{C}\right)$ & $\mathrm{Cal}\left({ }^{\circ} \mathrm{C}\right)$ & $\operatorname{Err}(\%)$ & $\operatorname{Exp}\left({ }^{\circ} \mathrm{C}\right.$ & $\mathrm{Cal}\left({ }^{\circ} \mathrm{C}\right)$ & $\operatorname{Err}(\%)$ \\
\hline \multirow{2}{*}{ Con_Cool } & 80 & 113 & 96 & 15 & 86 & 69 & 19.8 \\
& 160 & 140 & 128 & 8.6 & 112 & 99 & 11.6 \\
& 240 & 165 & 153 & 7.3 & 143 & 126 & 11.9 \\
GraO_0.1\% & 80 & 91 & 79 & 13.2 & 73 & 60 & 17.8 \\
& 160 & 125 & 109 & 12.8 & 99 & 87 & 12.1 \\
GraO_0.5\% & 840 & 156 & 133 & 14.7 & 129 & 113 & 12.4 \\
& 80 & 75 & 64 & 14.7 & 66 & 54 & 18.2
\end{tabular}


